\title{
Property Rights Revisited
}

\author{
May 19, 2020
}

\begin{abstract}
Over the last 20 years, a large number of papers have tried to quantify the effect of property rights on a wide range of variables like growth, trade and to a lesser extent, inequality. However, these studies have been inherently limited by measures of the security of property rights that are currently available. These suffer from any of a number of shortcomings, ranging from a lack of availability, objectivity, or the fact that they measure a broader concept like the rule of law. This paper tries to address this gap by proposing a new index of property rights. Specifically, we use a state-space model to combine all available indicators tracking the security of property rights into an index that covers 191 countries over the period 1994-2014. We compare it to the existing indicators by revisiting the link between inequality, democracy and property rights, using a panel threshold regression model with fixed-effects. Depending on the measure of property rights that is used, there can be considerable differences in the size, significance and even the sign of the estimated parameters. Specifically, in contrast with existing measures, we find that a strengthening of the security of property rights reduces inequality in highly democratic countries only via the government's redistribution channel.
\end{abstract}

JEL Codes: O38; O34; O17; H24; C32; O15

Keywords: Property rights; Institutions; Inequality; State-space model; Government redistribution; Panel threshold regression

\section{Introduction}

The last two decades have seen a number of studies that have tried to empirically determine the relationship between property rights and trade (e.g. Maskus and Penubarti, 1995), growth 
(e.g. Schneider, 2005; Goldsmith, 1995), inequality (e.g. Amendola et al., 2013), and many other macroeconomic variables. However, as most of these studies acknowledge, the measures tracking the security of property rights that are currently available are not without issues. Indeed, one major problem of the indexes that combine various measures, like the Fraser Institute's index used in Amendola et al. (2013), is that they often include aspects that are not directly related to property rights. Other measures, like the Heritage Foundation's indicator used by Goldsmith (1995), are potentially influenced by the political perception/leaning of their authors. Despite these problems, these indicators continue to be used because of a more pressing issue concerning the availability of the data. For example, while the index of patent rights of Ginarte and Park (1997), which is used by Schneider (2005), does not suffer from similar problems as the indicators above, it is only available on a five-yearly basis between 1970 and 1990. Consequently, researchers have been forced to make a trade-off between the methodological suitability and availability of the data.

In this paper, we attempt to address this issue by proposing a new index that strictly measures the security of property rights (PRP). The security of property rights is defined as "the degree to which the country's laws protect private property rights and the degree to which its government enforces those laws. This also includes the possibility that private property will be expropriated" (Teorell et al., 2013, p. 211). This definition is distinct from the more general rule of law, which captures the extent to which property rights are protected; but also includes indicators that "measure the success of a society in developing an environment in which fair and predictable rules form the basis for economic and social interactions" (Torell et al, 2019 p.657). Our proposed index, on the other hand, tries to measure the security of property rights by purging where possible elements such as those alluded in Torell et al. (2019). We do not imply this to mean that the other components of the rule of law, or the quality of governance do not affect property rights. However, this more strict definition is particularly useful when contrasting different components of the quality of governance or in empirical studies that focus specifically on property rights, especially when it is posited to have a non-linear effect (as is the case with inequality).

Starting from an overview of the strengths and weaknesses of existing measures on property 
rights, we select 18 indicators that strictly measure the security of property rights. Combining these indicators into a single index of property rights requires finding a solution to several technical problems, most importantly, the difference in the availability of the indicators: as much as $80 \%$ of the data is missing. Moreover, these indicators can also be markedly different: seven indicators are close-to continuous variables, four are truncated, while the remaining seven indicators are categorical data. To combine the indicators in a way that reflects the differences in their type, and that can handle missing observations, we use a state-space model. A state-space model is similar to the unobserved components model used in the construction of the Worldwide Governance Indicators (Kaufmann et al., 2009). The primary difference is that the state-space model also takes the temporal dependence into account. This is particularly interesting when creating an index of the security of property rights as this is likely to follow a random walk: barring any (legislative) changes, the security of property rights will be the same today as it was yesterday. By taking this temporal component into account, the state-space model can estimate with much greater certainty, particularly in the presence of missing observations.

The new PRP index provides an estimate of the security of property rights for more than 190 countries from 1994 to 2014 . As such, it significantly increases the data availability relative to the Heritage Foundation (15\% increase) and the Fraser Institute's indexes (45\% increase). While the overall correlation between the three indexes is high, this is entirely driven by a strong correlation in the average security of property rights of different countries. As we will show, the three indexes reach sharply diverging conclusions when used in panel data or time-series analyses. Finally, the PRP index is robust to our modelling choices, including the assumption about the behaviour of PRP over time, the treatment of categorical data, and other modelling choices

After constructing the index, we use it to re-examine the link between inequality and property rights. While the importance of property rights for growth and development has been firmly established, their effect on income distributions remains an open question. Theoretically, the extent to which property rights affect inequality will depend on whose property is being protected by the government. Property rights can worsen income inequality if they are designed to perpetuate the interests of advantaged minorities (Levi, 1988; Sened, 1997). On the other hand, 
as Besley and Persson (2013) note, property rights also increase the ability of the government to levy taxes and redistribute that income, which could lead to a decrease in inequality. In line with this, empirical analyses by Carmignani (2009) and Amendola et al. (2013) found that more secure property rights decrease inequality.

Our empirical analysis differs from the existing studies in a few ways. First, by using the newly constructed index of the security of property rights, we increase the number of countries covered. As we will show in section 3.2, the PRP index is also specifically designed to be used in panel data analysis, in contrast to e.g. the Worldwide Governance Indicators. Moreover, whereas most indicators take various aspects of the rule of law into account, our index is focused solely on the security of property rights. This allows us to separate its effects on income distribution from that of other institutional changes. Finally, we investigate the effect of property rights on income inequality before and after taxes and transfers.

The relationship between property rights and inequality is estimated using a panel threshold model, which allow us to explore the interplay between inequality, democracy and property rights. To be more specific, the approach allows us to estimate the effect of property rights on inequality at different democratic threshold levels, thus allowing for non-linearities in the relationship between inequality and property rights. We subsequently replicate our empirical analysis using the Fraser Institute index, the Worldwide Governance index and the Heritage Foundation index. In contrast to existing measures of property rights, we find that in more democratic countries the decrease in inequality caused by property rights is achieved via the government's redistribution. This finding offers support to Besley and Persson (2013) and Acemoglu et al. (2013) who highlight the distributive role of government on the effectiveness of property rights.

The paper proceeds as follows. In the next section, we discuss available data on the security of property rights and section 3 outlines the construction of the new PRP index. Section 4 then uses the PRP index to take another look at the relationship between property rights and inequality. Section 5 concludes. 


\section{Indicators of property rights}

\subsection{Singular indicators of property rights}

As is the case with most indicators of governance, there is little to no objective data available that can be used to compare the security of property rights across countries. Instead, what is most often used when studying (the effects of) property rights are perception-based indicators: survey data or expert assessments that capture the opinion of experts, business leaders, or people working for the government and multilateral organisations. We combined a dataset of 18 such indicators from seven different sources. The selection criterion of these indicators is whether they directly measure the 'degree to which a country's laws protect private property rights and the degree to which its government enforces those laws, including the probability that private property is expropriated.' Excluded are those variables that even though they can affect the security of property rights, measure other aspects of governance and the rule of law. While it is difficult to claim that our list of indicators measuring the security of property rights is complete, we do include all appropriate indicators from both the Worldwide Governance Indicators and the Economic Freedom of the World report. We will label these singular indicators to distinguish them from the combined indexes. A summary of their descriptive statistics can be found in Table 9 (Appendix A).

- The Economist Intelligence Unit's (EIU) market indicators and forecasts dataset is a commercially available dataset containing expert assessments on various economic and political characteristics of 60 countries from 1995 to 2015. It includes two indicators that assess the 'protection of property rights' and the 'protection of intellectual property rights,' whose scores range from very low (1) to very high (5), in increments of 0.1 .

- The second source of data on property rights is CEPII's Institutional Profiles Database (IPD) which is available for 143 countries from 2001 to 2012 (with gaps). In cooperation with the French government, CEPII sends out surveys on the perception of the institutional framework to the regional offices of the French development agency and the Economic Services of the Ministry for the Economy and Finance. These survey questions are translated into 130 indicators covering various aspects of the institutional framework, six 
of which deal directly with property rights: i) what is the effectiveness of legal measures to defend property rights between private agents; ii) does the government exert arbitrary pressure on private property; iii and iv) is there compensation in the event of de jure or de facto expropriation of (land) property; $\mathrm{v}$ and vi) is intellectual property protected in terms of counterfeiting or manufacturing secrets, patents, etc.; and vii) does the state formally recognise the diversity of land tenure system? The IPD indicators are all scored 1, 2, 3 or 4 , with higher scores corresponding to greater security of property rights. The only exception is the seventh IPD indicator which works with increments of 0.5.

- Global Insight, a division of the Information Handling Services (IHS), provides expert assessments on Business Risk and Conditions in 189 countries. Included in their 2015 dataset is an indicator of the risk of expropriation that ranges from no risk (0) to violent risk (10) in increments of 0.1 . We inverted the values such that a higher score corresponds to less risk.

- As part of their World Competitiveness Yearbook (WCY), the Institute for Management Development conducts an executive opinion survey. Among their questions on the institutional quality of countries, this survey asks business leaders' opinion on i) the enforcement of intellectual property rights and ii) the protection of personal security and private property rights. Both indicators are scaled from 0 (no protection) to 10 (strong protection) in increments of 0.01. They are available for 61 countries from 1995 to 2015.

- Similarly, the World Economic Forum's Global Competitiveness Report (GCS) tracks business leaders' opinion on the protection of both property rights and intellectual property rights. The survey is available for more than twice the number of countries (151) and started in the late 1970s. However, we only have access to the 2006 to 2015 data. Property rights are scored on a continuous scale from 1 (lowest) to 7 (highest).

- The Heritage Foundation (HTF) publishes an assessment of the protection of property rights that covers almost 180 countries from 1994 to 2013. The indicator ranges from an outlawing (0) to a guarantee of private property (100) in increments of 5.

- Finally, the Country Policy and Institutional Assessment (CPIA) is a diagnostic tool used 
to analyse the institutional framework of countries around the world. Specifically, CPIA contains an indicator that captures the extent to which property rights and rule-based governance offer protection, ranging from none at all (1) to strong protection (6). This assessment is performed by several multinational organisations, including the World Bank (WBD), the African Development Bank (ADB) and the Asian Development Bank (ASD). Combined, they cover 86 countries from the mid-2000s to 2014. ADB and WDB both work with increments of 0.5 , but the ASD is more fine-grained and works with increments of 0.01 .

\subsection{Combined indexes of the security of property rights}

There are two main problems with existing indicators of property rights. First, as shown in Table 9 (Appendix A), most indicators of property rights are only available for a small set of countries or years. Using any one of these indicators in an empirical study is bound to have a significant effect on the sample selection, which might influence the results (i.e., selection bias). Second, as the data essentially captures perceptions, using only the information from a single source runs the risk that this source's preconceptions and (political) biases distort the analysis. For example, the index of property rights that by far has the broadest coverage is published by the Heritage Foundation, which has a very distinct political (i.e., conservative) leaning. As noted by Goldsmith (1995, p.164) this Heritage Foundation's index is 'part of a long-standing campaign against US development assistance [...] Given the Heritage Foundation's political goals, the property rights rating system must be viewed with scepticism.'

One way to resolve both problems is to combine indicators from different sources into an index of the (perception of) the security of property rights, thereby reducing the risk of bias and increasing the coverage. The underlying assumption is that the measurement errors are uncorrelated over different sources, making a combined index more reliable than the singular indicators. There is always the possibility that the different indicators influence each other, which would mean that their measurement errors are also correlated. However, by using information from different types of sources (from commercial risk agencies to expert assessments by NGOs and government agencies), this risk should be minimal. 
As far as we can tell, there are currently three such indexes that are frequently used in research. The first index is part of the Worldwide Governance Indicators (WGI), which amalgamates various indicators of governance into six indexes tracking specific aspects of the institutional framework. ${ }^{1}$ The index starts in the mid-1990s and covers more than 200 countries. As part of its index of the rule of law, the WGI combines the indicators of property rights outlined above, together with indicators of, e.g., the incidence of violent crime, muggings and assaults, confidence in the police force and human trafficking (Kaufmann et al., 2009). In other words, the WGI measures a much broader concept than just the security of property rights as it includes many other components tracking the strength of the rule of law. To combine these indicators, Kaufmann et al. use an unobserved components model that assigns statistical weights to each indicator depending on their reliability and differences in scaling (cf. supra). The index values are subsequently normalised such that the mean and standard deviation in each year are respectively zero and one.

The second index is part of the 'Economic Freedom of the World' report published by the Fraser Institute (FRA) and covers 159 countries from as early as 1970. The subindex that measures the 'strength of the legal system and property rights' combines nine indicators that capture various aspects of the institutional framework (Gwartney et al., 2019, p.227). Strictly speaking, only one indicator in this index directly measure property rights: i) protection of property rights from the Global Competitiveness Report. The remaining indicators measure tangential aspects of the legal system: ii) Judicial independence; iii) impartial courts; iv) military Interference in rule of law and politics; v) integrity of the legal system; vi) legal enforcement of contracts; and vii) regulatory costs of the sale of real property; viii) reliability of police; and ix) business costs of crime. Each component is first rescaled to lie between 0 and 10 and is then combined using a simple average. Like the WGI, this index's coverage is too broad for our purpose. While the e.g. impartiality of the courts will also affect the security of property rights, it also incorporates many aspects that are not directly related.

\footnotetext{
${ }^{1}$ The six categories covered by WGI are i) voice and accountability; ii) political stability and lack of violence; iii) government effectiveness; iv) regulatory quality; v) rule of law; and vi) control of corruption.
} 
Finally, there is also the index of patent rights created by Ginarte and Park (1997), which covers 110 counties every five years from 1970 to 1990 . There are two essential differences between GP97 and the indexes and indicators described above. The first is that GP97 focuses on patent rights, rather than the more general property rights. Second, GP97 does not measure the perception of property rights protection but instead keeps track of the existence of laws and membership of international agreements aimed at protecting patents rights. ${ }^{2}$ In other words, while the other indicators measure the (perceived) security of property rights, GP97 focuses on the presence of specific systems aimed at protecting patent rights. While we expect a high correlation between the two, many factors can cause them to diverge, e.g., how 'special, countryunique practices of the law' affect enforcements rights (Ginarte and Park, 1997, p. 228). On the other hand, by relying on objective, rather than perception-based, data, the authors can go back much further in time.

\section{A new combined index of the security of property rights}

Our goal in this paper is to propose an index that strictly measures (the perception of) the security of property rights, separately from other aspects of the rule of law. Focusing on property rights alone allows us to disentangle its effect from that of the overall quality of the judicial system and other aspects of the institutional framework. This will ensure a better match between the theoretical models and empirical tests on the effect of property rights. To the extent possible, we have tried to limit the technical explanation of the construction of the index to section 3.2 and appendix B, which the less technically-inclined reader should be able to skip without sacrificing overall understanding.

${ }^{2}$ GP97 considers five aspects of patent rights: i) extent of coverage; ii) membership in international patent agreements; iii) provisions for loss of protection; iv) enforcement mechanisms and v) duration of protection. Each aspect is assigned a score between zero and one, after which the index is constructed by taking the sum over all aspects. This results in a score for each country between 0 and 5 . 


\subsection{Data selection}

The PRP index combines all publicly available information on the perception of the security of property rights. Using only perception data precludes the use of GP97. Moreover, the difference in the coverage between GP97 and the rest of the dataset means that it would have been difficult to include this information. The GP97 dataset ends in 1990, whereas the earliest other indicators are available is 1994 (see Table 9, in Appendix A).

There are two additional selection criteria for the data. First, as there already are combined indexes that measure the strength of the rule of law, we focus strictly on indicators of property rights. Second, when possible, we use the source data in its most disaggregated form. The reason is that aggregating indicators by source hides their underlying variability. Consider, for example, a source containing two indicators, with country A having an intermediate score on both $(0.5$ and 0.5$)$ and country B having diverging scores (0.1 and 0.9). Averaging out those scores for that source would give the impression that both countries perform similarly. While these selection criteria rule out FRA and WGI indexes, it should be noted that all indicators related to property rights contained in either index are included in PRP separately.

Following these rules, we are left with the 18 singular indicators of property rights described in section 2.1. It could be argued that the CPIA indicators should also be excluded as they cover 'property rights and the rule of law.' While our baseline results include the ADB, ASD and WBD indicators, the robustness section (appendix B.3) discusses how the index changes when they are left out.

Putting these indicators together, we have information on 191 countries from 1994 to 2014. However, there are many missing observations. For example, no country is covered by all indicators, and one in four countries is examined by less than a quarter of the indicators. Overall, data availability is only $20 \%$ but reaches close to $50 \%$ in 2009 and 2012 -two of the years in which the IPD is available. These gaps in the dataset and the differences in availability of the various indicators have to be accounted for when these indicators are combined. If the index is instead computed with whatever data is available, the actual shifts in the security of property rights would be indistinguishable from changes in the availability of the underlying indicators.

Not only does the coverage of the indicators differ, so does their data type. Firstly, some 
indicators might be truncated, meaning that they take on values that are equal to the theoretical minimum or maximum and we cannot rule out that the actual value of the index should be lower or higher. Table 9 (Appendix A) compares each index's theoretical range with its sample range, revealing that the values of the EIU, HTF, IPD, ADB, ASD, and WBD indicators are often equal to their theoretical extremes. For example, in the case of the second EIU indicator, as much as $40 \%$ of its observations are equal to either the minimum (1) or maximum (5) value. Second, except for the GCS data, all indicators are count data: they only take a limited number of values. This is not a problem for most variables as the incremental steps they work with are small, given their range. For example, the HTF indicator takes as many as 20 different values. However, as can be seen in the last column of Table 9, the ASD and WBD indicators only have 7 or 8 unique values, and six of the IPD indicators can only assume one of four possible values.

In summary, our dataset can be separated into three groups. The first contains the count indicators, which consists of those that only take on eight or fewer unique values. One of the robustness checks examines how the index changes when we change the threshold to four unique values or fewer (Appendix B.3). The remaining indicators are treated as continuous. Within this group, we separate the truncated indicators, which have values that are equal to the theoretical minimum or maximum.

\subsection{Methodology}

As we outline above, to combine the different indicators of property rights in a meaningful way, we have to find a method that can handle a dataset where $80 \%$ of the information is missing. The fact that the underlying availability of the indicators changes so drastically over time makes the more common methods of indexation -like a simple average, principal component analysis or even an unobserved components model- less appropriate. As new indicators become available, the value of the index would keep changing even when the underlying security of property rights does not. One way to decrease the number of missing data points, which is employed e.g. by the WGI, is to take the average values per source and impute the survey data before computing the index. However, it is hard to keep track of how this affects the index values, and it artificially decreases the confidence intervals of the index values. As an alternative solution, we follow 
Standaert (2015) and combine the indicators using a state-space model, which has a straightforward solution to missing data. Because the state-space model keeps track of the dynamic aspects of property rights, it does not require any ex-ante imputation or other manipulations of the data. Moreover, by accounting for the dynamic aspect of property rights, more information used in the estimation of every single value of the PRP index, greatly increasing the certainty of our index values. Another advantage of the state-space model is that it can be easily expanded to take into account the fact that certain variables are truncated or only take a limited number of values, allowing us to fully adjust our methodology to match the characteristics of the data.

The state-space model is related to the unobserved component model (UCM) that Kaufmann et al. (2009) use to construct the Worldwide Governance Indicators. Like the UCM, the statespace model treats the security of property rights as a real, but unobserved characteristic of a country called a state-variable. The observed indicators are attempts at measuring this state variable but are prone to various errors, like measurement errors or conceptual differences in what is being measured. By combining the information from various indicators, the UCM and statespace model can start to identify the state variable from statistical noise. The more information is added and the higher the quality of that information, the greater the precision with which the state-variable can be identified. The difference between the state-space model and the UCM is that the former also takes the possibility into account that the unknown security of property rights in year $t$ depends on the level in the preceding year, $t-1$. From a theoretical point of view, we expect a high level of persistence in property rights as it is determined by factors that tend to change only very gradually like the rules, laws and the institutional framework. The state-space model exploits this temporal dimension and makes maximum use of the available data to estimate the level of protection with much greater precision. Moreover, the state-space model also has a straightforward approach to the problem of missing values. ${ }^{3}$

${ }^{3}$ Given the appropriate restrictions, the state-space model can be reduced to a simple average, PCA or UCM. E.g. if we assume that the time-dependence is zero, the state-space model is reduced to a UCM. If we further assume that all underlying indicators are equally reliable, it returns a PCA analysis. Assuming that all indicators are related to the security of property rights in the same way gives us a simple average. 
A state-space model is composed of two parts. The first is the state equation (Equation 1) that describes the dynamic behaviour of the unknown state variable. In this case, the unknown state variable is the security of property rights, $P R P_{i, t}$, for country $i$ at time $t .^{4}$ As we expect property rights to depend on its previous values in a fairly straightforward way, we model the state equation as an autoregressive model with one lag (AR-1). The exact extent to which the security of property rights depends on previous values is captured by the parameter $\left(\phi_{i}\right)$, which is assumed to be different for each country. Deviations from the expected pattern are captured by the $\mu_{i, t}$, which are assumed to follow a Normal distribution. ${ }^{5}$ Furthermore, $\phi_{i}$ is restricted to lie in the interval $[-1,1]$ to ensure that the model remains stable. ${ }^{6}$

$$
\begin{aligned}
P R P_{i, t} & =\phi_{i} P R P_{i, t-1}+\mu_{i, t} \\
\mu_{i, t} & \sim N\left(0, \sigma_{\mu}\right)
\end{aligned}
$$

\footnotetext{
${ }^{4}$ While the state-space model can be used to identify multiple state-variables, we limit ourselves to one common signal for a number of reasons. The most of which is that we do not expect there to be multiple signals in the property rights indicators. Given that all indicators measure property rights in a strict sense, it makes sense that there is only one common component to all indicators. We confirm this using an exploratory principal component analysis (using alternating least squares to account for missing data). This analysis shows that there is one main component that accounts for most of the variation in the data.

${ }^{5}$ To ensure that the model is identified, the variance $\sigma_{\mu}$ is normalised to one (see Kim et al., 1999, chapter 8). As a result, $\phi_{i}$ is the only variable that captures the persistence in the security of property rights.

${ }^{6} \mathrm{It}$ is important to note here that the imposition of an (AR-1) process does not mean that we impose that the security of property rights converge to a long term stable equilibrium value (i.e. zero). Firstly, the time-dependence parameter $\phi_{i}$ can be one, in which case property rights follow a random walk which does not converge to a long term value. Secondly, when the value of $\phi_{i}$ for a particular country is less than one, the value would only converge to zero if the indicators of property rights offer no contradicting information in the measurement equation. As we do not use the state-space model to extrapolate data, this is hardly ever the case.
} 
The second part of the state-space model is a set of measurement equations -one for each of the indicator- that express how the indicators are related to the unknown security of property rights. Depending on the exact nature of the indicator, one of three equations is possible. Indicators that are not truncated and that can assume a relatively wide range of values (like the GCS indicators) are modelled in a simple linear measurement equation. If $y^{a}$ denotes such an indicator, its measurement equation takes the following form: ${ }^{7}$

$$
\begin{aligned}
y_{i, t}^{a} & =c^{a}+z^{a} P R P_{i, t}+\epsilon_{i, t}^{a} \\
\epsilon_{i, t}^{a} & \sim N\left(0, \sigma_{\epsilon}^{a}\right)
\end{aligned}
$$

The intercept and slope parameters $\left(c^{a}\right.$ and $\left.z^{a}\right)$ adjust the scaling of the indicator to that of the $P R P$ index. Since each indicator uses a different scaling, these parameters are assumed to be different for all indicators. The measurement equation also includes an error term that captures, e.g., measurement errors or conceptual differences. The precision of a specific indicator is captured by the variance of the error term, $\sigma_{\epsilon}^{a}:$ the less reliable an indicator is, the higher this variance will be. This variance will differ for each indicator, both to capture differences in scaling as well as differences in the reliability of each indicator. The baseline model ignores potential cross-correlation between the measurement errors of the different indicators, mainly because the structure in the missing data does not allow us to model this systematically.

Now consider an indicator, $y^{b}$, whose values are truncated at a minimum, $l^{b}$, and maximum value, $u^{b}$. In our dataset, there are four such indicators: EIU1, EIU2, HTF, and WBD. To capture the possibility that the values of these variables are truncated, we augment the state-space model with a latent variable $\tilde{y}^{b}$ whose values can exceed the theoretical maxima of $y^{b}$. The values of this new latent variable, $\tilde{y}^{b}$, are equal to that of the original variable whenever the latter lies between the minimum and maximum. However, for those values of $y^{b}$ that lie at the minimum,

${ }^{7}$ For notational convenience, we denote the vector formed by stacking up all observations by dropping the subscript $t$ :

$$
y^{a}=\left[y_{1,1}^{a}, y_{1,2}^{a}, \ldots, y_{n, T}^{a}\right]^{\prime}
$$


we allow the values of the latent variable to be equal to, or less than the minimum.

$$
y_{i, t}^{b}= \begin{cases}l^{b} & \text { if } \quad \tilde{y}_{i, t}^{b} \leq l^{b} \\ u^{b} & \text { if } \quad \tilde{y}_{i, t}^{b} \geq u^{b} \\ \tilde{y}_{i, t}^{b} & \text { otherwise }\end{cases}
$$

In other words, we combine a (Bayesian) Tobit regression approach with our state-space model (Koop, 2003, p. 212-213). This latent variable can then be used in the same linear measurement equation used for $y^{a}: 8$

$$
\begin{aligned}
\tilde{y}_{i, t}^{b} & =c^{b}+z^{b} P R P_{i, t}+\epsilon_{i, t}^{b} \\
\epsilon_{i, t}^{b} & \sim N\left(0, \sigma_{\epsilon}^{b}\right)
\end{aligned}
$$

Finally, we have to consider those variables that only take a limited number of values: IPD1IPD6 and to a lesser extent IP7, ADB and WBD. Like the truncated variables, we can solve this problem by augmenting the model with a latent continuous variable, as is done in the Bayesian the estimation of ordered Probit models (Koop, 2003, p. 218-220). If $y^{c}$ is an ordinal variable that takes values $\{1,2, \ldots, J\}$, we can write the following linear measurement equation using the continuous latent variable $\tilde{y}^{c}$ :

$$
\begin{aligned}
& \tilde{y}_{i, t}^{c}=c^{c}+z^{c} P R P_{i, t}+\epsilon_{i, t}^{c} \\
& y_{i, t}^{c}=\left\{\begin{array}{cccc}
1 & \text { if } & \gamma_{0}^{c}< & \tilde{y}_{i, t}^{c} \leq \gamma_{1}^{c} \\
2 & \text { if } & \gamma_{1}^{c}< & \tilde{y}_{i, t}^{c} \leq \gamma_{2}^{c} \\
\vdots & \\
J & \text { if } & \gamma_{J-1}^{c}<\tilde{y}_{i, t}^{c} \leq \gamma_{J}^{c}
\end{array}\right. \\
& \epsilon_{i, t}^{c} \sim N(0,1)
\end{aligned}
$$

${ }^{8}$ The value of $\tilde{y}^{b}$ below $l^{b}$ is determined by the truncated measurement equation (Equation 6): $E\left(\tilde{y}_{i, t}^{b} \mid P R P_{i, t}\right)=c^{b}+z^{b} P R P_{i, t}$, but are of course restricted to be equal to or less than the minimum value. The same applies to the observations that are truncated at the maximum value. Exactly how we do this is described in detail in appendix B. 
The parameters $\left\{\gamma_{0}^{c}, \ldots, \gamma_{J}^{c}\right\}$ are the cut-off values that map the latent variable on the ordered variable $y^{c}$. As was the case with the truncated variables, the expected value of the latent variable is given by the ordered probit measurement equation (Equation 8): $E\left(\tilde{y}_{i, t}^{c} \mid P R P_{i, t}\right)=$ $c^{c}+z^{c} P R P_{i, t}$. At the same time, if $y_{i, t}^{c}=j, \tilde{y}_{i, t}^{c}$ is restricted to lie in the interval $\left.] \gamma_{j-1}^{c}, \gamma_{j}^{c}\right]$. Since the range of $\tilde{y}^{c}$ is all real numbers, the last and first values of $\gamma^{c}$ are plus and minus infinity. Furthermore, to ensure that the model is identified $\gamma_{1}^{c}$ is set to zero and the variance of the error term $\sigma_{\epsilon}^{c}$ is normalised to one (see Koop, 2003, p. 219).

Combining the measurement equations for all indicators (Equations 3-10) together with the state-equations (Equations 1-2) gives us the state-space model that can be used to estimate the security of property rights. The actual estimation of the index uses iterative techniques called the Kalman filter, which iterates forward in time, and Kalman smoother, which iterates backwards. Assuming we know the security of property rights at $t-1$, the Kalman filter will first predict the level of security at $t$ using the state-equation. This prediction is then compared with the indicators of property rights using the measurement equation. If the indicators deviate from the predicted level, the prediction is adjusted. Depending on how reliable that indicator is, the information contained in it will be granted more or less weight than the initial prediction. After the Kalman filter has run through all observations, the Kalman smoother iterates backwards to ensure that future information is also taken into account. The precise algorithm we use is explained in the appendix B, but for a detailed description state-space models and the Kalman filter and smoother, see Kim et al. (1999, chapter 3 and 8).

A notable advantage of explicitly taking the persistence in the security of property rights into account is that it gives us a straightforward solution to the problem of the missing variables in the dataset. If an observation is missing, we set it to zero and at the same time label that observation as utterly unreliable by setting the variance of the error term in the measurement equation to infinity. In other words, we replace missing data with data that has no informational value. Because the model links the security of property rights over time, the index can still be computed even when only a couple of indicators are available. The availability does affect the certainty with which the index is computed: the more information is missing, and the lower the quality of the available variables, the higher the uncertainty of PRP index will be. By taking 
this uncertainty into account in any subsequent analysis, we can ensure that our analysis is not distorted by the presence of missing observations in the dataset, as suggested by Standaert (2015) and Desbordes and Koop (2015).

To improve the interpretability of the index, we rescale the index values such that a country that has the lowest possible score in all years has an index value of zero, while a country that has the maximum score on all components has the maximum score of 100 (see appendix B.2).

Finally, appendix B.3 discusses the robustness of the PRP index to the data selection and modelling choices. It describes how the index changes when a random indicator is left out or when the data selection is restricted to indicators that only measure property rights. It also tests the effect of grouping the data by source, defining ordered variables as having no more than four unique values and what the effect is of assuming that the security of property rights follows a unit root. Finally, we also check how our results are affected by the use of the Kalman smoother. Overall, the effect of these changes to the data selection and the specification of the state-space model are minimal.

\subsection{The security of property rights index}

At the start of the dataset in 1994, the PRP index covers only 100 countries, but this number steadily increases until it reaches over 190 countries in the late 2000s. While in theory, the index runs from 0 to 100, the actual values lie between 44 (Venezuela in 2014) and 60 (Finland and Switzerland in 2014). Like the singular indicators, higher values of the index mean more secure property rights. The 2014 values are shown in Figure 1, with darker colours indicating higher values.

Most of the variation in property rights stems from differences between countries. In contrast, the security of property rights remains stable over time for the majority of countries. To illustrate, Figure 2 plots the PRP index values over time for the United States, Rwanda and the Bolivarian Republic of Venezuela. Rwanda (Venezuela) is the country with the most substantial increase (decrease) in the dataset, but for most countries, the pattern in the PRP values resembles that of the USA. Relative to the size of the $95 \%$ confidence intervals, it would seem that none of these changes is significant. We can use the large sample of draws from the distribution of the 


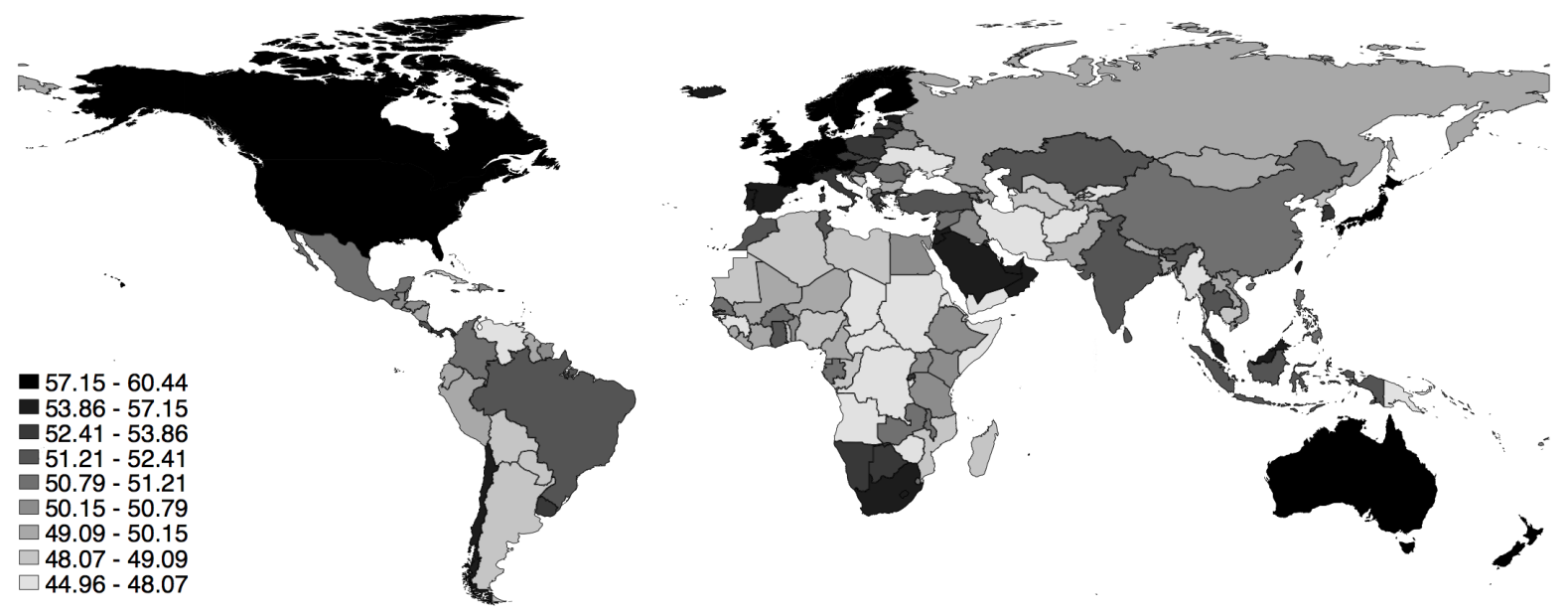

Figure 1: Security of property right in $2014($ darker $=$ more secure $)$

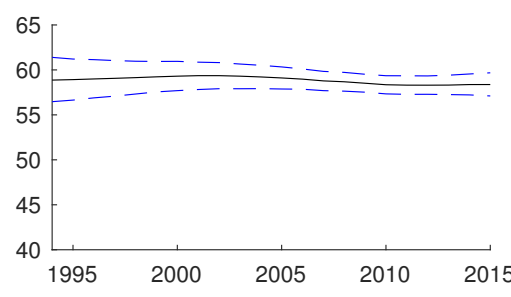

(a) USA

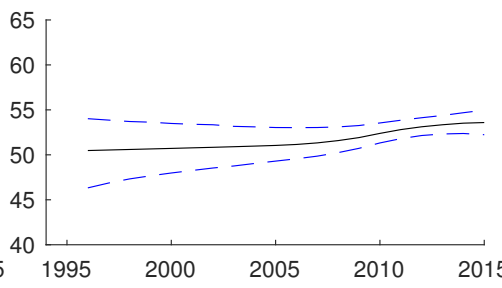

(b) Rwanda

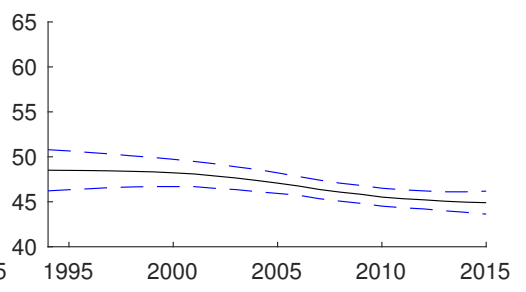

(c) Venezuela

Figure 2: The security of property rights over time PRP index (black line) and its 95\% confidence interval (blue dotted lines).

PRP values to determine which of the changes in PRP are statistically significant. ${ }^{9}$ This reveals that there are only 30 countries for which the change in PRP is significant at the $10 \%$ level, nine countries at the 5\% level and three countries (including Rwanda) at the $1 \%$ level.

Table 1 compares the PRP index to the other indexes of property rights. The Fraser Institute's index (FRA), Worldwide Governance Indicators' index of the rule of law (WGI) and the Heritage Foundation index (HTF) are all highly correlated with PRP (at least 0.88). However, this is invariably driven by a strong cross-sectional (between) correlation. The within correlation shows that the changes over time can be markedly different depending on the index. Relative to FRA and HTF, the PRP index also constitutes a significant increase in the coverage of the dataset (respectively a 15\% and $45 \%$ increase). Finally the last row of Table 1 shows the cross-sectional correlation between the 1990 values of the Ginarte and Park (1997) index of patent rights with

\footnotetext{
${ }^{9}$ If the PRP increases in more than $95 \%$ of the draws, the increase is deemed significant at
} the $95 \%$ level. 
the 1994 values of the PRP index. While both indexes are positively correlated, the differences are larger than with the other indicators.

Table 1: Comparison between PRP and other indexes of property rights

\begin{tabular}{l|ccc|ccc}
\hline & \multicolumn{3}{|c|}{} & \multicolumn{4}{c}{ Correlation with PRP } \\
Indicator & Obs. & Countries & Years & Overall & Between & Within \\
\hline PRP & 3749 & 191 & $1994-2015$ & - & - & - \\
& & & & & & \\
FRA & 1986 & 141 & $1970-2015$ (with gaps) & 0.892 & 0.923 & 0.112 \\
HTF & 3161 & 179 & $1994-2013$ & 0.881 & 0.867 & 0.317 \\
WGI & 3752 & 214 & $1996-2016$ (with gaps) & 0.935 & 0.94 & 0.377 \\
& & & & & & \\
GP97 & 749 & 107 & $1960-1990$ (with gaps) & - & $0.506^{(a)}$ & - \\
\multicolumn{7}{l}{ (a) Correlation between the last values of GP97 in 1990 and the first value of the PRP index in 1994 }
\end{tabular}

Figure 3 compares the PRP index with the singular indicators of property rights it combines. It shows that the PRP index explains most of the variation in these indicators. Half of the indicators have a correlation coefficient that is greater than 0.85 , and only two indicators (IPD2 and IPD7) have one that is less than 0.5. When we divide the indicators per type of source, we see that the index equally represents the business survey data, the assessments of multilateral organisations, commercial risk agencies, think tanks and governments. Only the expert assessment by government officials from the Institutional Profiles Database has a lower correlation (0.36-0.74). However, this can also because the questions relate to specific aspects of the security of property rights, like the recognition of the diversity of the land tenure system (IP7).

Splitting up the correlation into the between and within correlation (panel b and c of Figure 3, respectively) reveals a similar pattern to Table 1, namely that the correlation between the average values of each country is very high, while the change over time in each indicator is much lower. The main reason is that the pairwise within correlations of the singular indicators of property rights is extremely low as well. The average within correlation is only 0.037 , and less than $4 \%$ of the correlations is higher than 0.4. ${ }^{10}$ The lack of agreement between the singular indicators on the direction of movement in the security of property rights explains why the change over time in the PRP is so gradual (cf. Figure 2) and why many of the changes over time are not significant.

\footnotetext{
${ }^{10}$ Table available upon request.
} 
This is further evidence of the need to use a technique like the state-space model to combine the information from the different indicators. By taking the information on the dynamic behaviour of property rights into account, the state-space model is much better suited at filtering out random measurement errors and identifying the actual changes in the security of property rights. It also strongly cautions against the use of the other indicators in a panel data analysis. Neither the Heritage Foundation nor the Fraser Institute's index provide an estimate of their reliability and the changes in their indexes can be driven by changes in the availability in the underlying data or other measurement errors. While the Worldwide Governance Indicators include an estimated standard error, their construction does not allow them to be used in panel data studies. ${ }^{11}$

A final advantage of the PRP index over e.g. the Heritage Foundation and the Fraser Institute's indexes is that it provides an estimate of its reliability. Like the Worldwide Governance Indicators, we estimate the standard deviation and confidence interval of each value of the PRP index. These reflect the availability and quality of the underlying data: i.e. the more, higherquality data is available, the smaller the confidence bands are. This can be seen in the plot of Rwanda's PRP index over time (Figure 2): its confidence bounds steadily decrease as the number of available indicators increases from 1 in 1994 to 10 in 2012. In addition, the estimation procedure of the PRP index also returns hundreds of draws from the distribution of each observation, allowing us to fully take the reliability of the PRP index into account in any subsequent computation or regression.

Finally, it should be noted that the security of property rights is also strongly correlated with the level of development. However, this strong correlation is also entirely driven by the crosssectional relation between both variables. In any given year, the correlation between property rights and (the log of) GDP per capita can be as high as 0.8 , while the correlation of their variation over time is only 0.11 .

\footnotetext{
${ }^{11}$ The WGI values are normalised such that the average value and standard deviation in each year are respectively zero and one.
} 


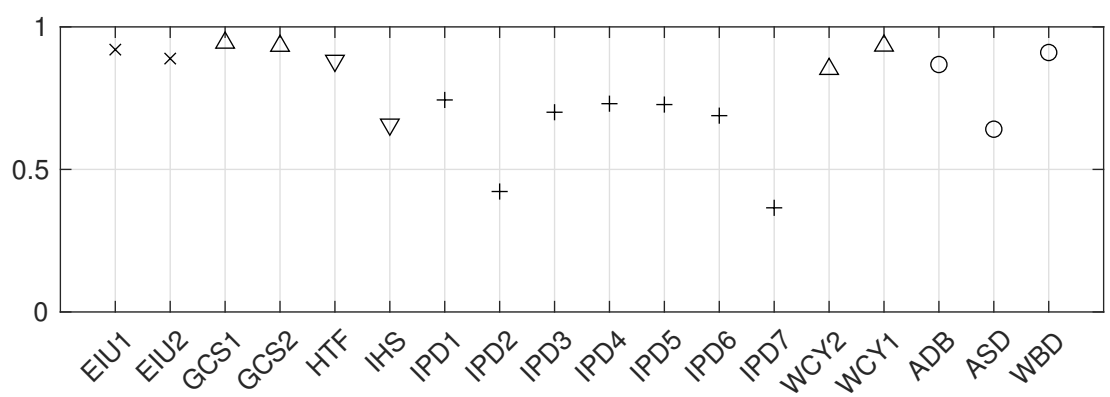

(a) Overall correlation

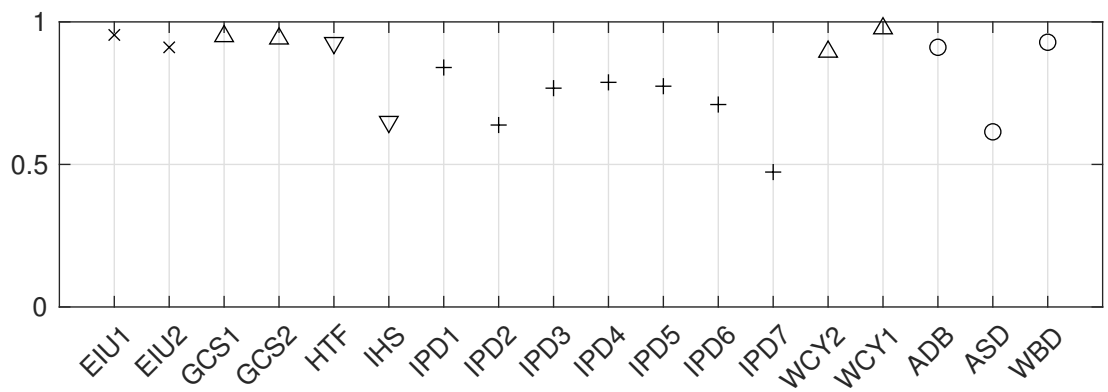

(b) Between correlation

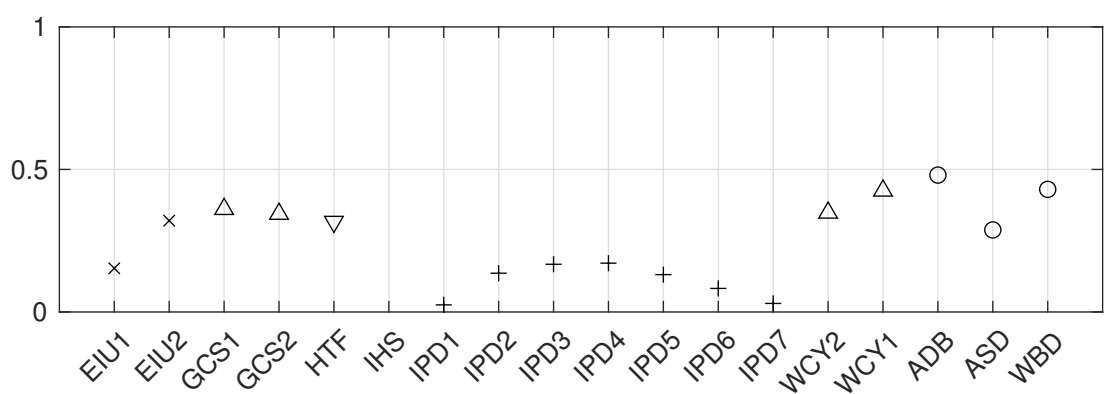

(c) Within correlation

Figure 3: Correlation between PRP and its constituent singular indicators

Correlation between the PRP index and its 18 constituent indicators (cf. section 2.1). The correlations are split up by the type of source with $\triangle$ referring to cross-country surveys of firms and the other indicators signalling expert assessments by a multilateral organisation $(o)$, by commercial risk agencies $(\mathrm{x})$, by think tanks $(\nabla)$ or by the government $(+)$.

\section{Property rights and inequality revisited}

\subsection{Related literature}

We use the new index of property rights to investigate the relationship between property rights and inequality. Theoretically, property rights could worsen or improve inequality depending on the actions of the government. First, if the government design property rights in a way that they perpetuate the interests of advantaged minorities, then the income distribution will worsen. Along these lines, Levi (1988) remarks that a revenue-maximising government would protect 
the rights of those who yield the highest return to their investment in property rights, namely the middle class; a view also shared by Sened (1997). The main argument put forward by proponents of this view is that only the middle class has the incentive to create prosperity and wealth, which are crucial for governments relying on tax revenues. While the security of property rights is a crucial instrument for governments to maximise their utility, it will inevitably result in more inequality (Piketty, 2013). On the other hand, if the extractive government uses the generated funds for redistributive purposes, then inequality is likely to be reduced. Further, Besley and Persson (2013) posit that as property rights increase the cost of the informal economy, they make it easier for the government to tax and redistribute. In short, this implies that while the direct effect of property rights may increase inequality, its indirect effect may reduce it. Further, Acemoglu et al. (2013) note that the effect of property rights interacts with democracy, as the latter influences the government's propensity to redistribute.

While several studies have explored the link between institutions, broadly speaking, and inequality (see Muller, 1988; Moon, 1991; Rodrik, 1999; Li et al., 1998; Reuveny and Li, 2003; Chong and Gradstein, 2007; Reuveny and Li, 2003; Sirowy and Inkeles, 1990; Lee, 2005; Acemoglu et al., 2013; Bennett and Nokolaev, 2017) only a limited number have paid attention to the link between property rights and inequality. For example, Carmignani (2009) found that property rights worsen inequality in a sample of 120 countries. Similarly, Amendola et al. (2013) show that strengthening the security of property rights increases income inequality in developing countries. In contrast, Young and Lawson (2014) find that legal system and property rights have no significant effect on labour shares for a sample of 93 countries.$^{12}$ In a similar vein de Haan and Sturm (2015) show that the Fraser index adjusted for the government size and sound money has no significant effect on inequality. ${ }^{13}$

\footnotetext{
${ }^{12}$ Albeit for a sample of OECD countries they find a positive and significant effect.

${ }^{13}$ Other studies have explored the link between the Economic Freedom Index and inequality. Bennett and Nokolaev (2017) provides a good review of recent contributions.
} 


\subsection{Empirical specification}

In this paper, we investigate whether the effect of property rights on inequality is contingent on the level of democracy. Put differently, we explore whether the distributional effect of property rights are the same in low and high democracies. Given that democracy affects the government's propensity to redistribute, as pointed out by Acemoglu et al. (2013), one would expect property rights to potentially reduce inequality in higher democracies. This view is also shared by van de Klundert (2010), who points to the distributive effect of democracy. Furthermore, Harms and an de Meulen (2013) stated that in addition to their direct effect, institutions may exert an indirect effect on the security of property rights. They maintain that institutions may either undermine or foster the impact of diverse interests policy choices depending on how strongly governments reflect the preferences of the majority.

To achieve our objective, we adopt a threshold panel data technique with fixed-effects. While the focus is on the new index of property rights (PRP) we also report the results using alternative measures of property rights.

The basis of our empirical model draws from the existing literature by first specifying a linear regression equation as follows:

$$
\text { Gini }_{i, t}=v_{i}+\gamma P R P_{i, t}+x_{i, t}^{\prime} \beta+\epsilon_{i, t}
$$

Where Gini is the outcome of interest, i.e., inequality in country $i \in\{1, \ldots, n\}$ at time $t \in$ $\{1, \ldots, T\}$; PRP is our measure of property rights; $x_{i, t}^{\prime}$ is the set of covariates; and $v_{i}$ and $\epsilon_{i, t}$ denote, respectively, an unobserved individual fixed effect and a zero-mean idiosyncratic random disturbance.

To account for the interplay between property rights, democracy and inequality we follow (Fouquau et al., 2008) and introduce threshold effects to (Equation 11). Our panel threshold model is specified as:

$$
G i n i_{i, t}=\gamma P R P_{i, t}+x_{i, t}^{\prime} \beta+\left(\hat{\gamma} P R P_{i, t}+x_{i, t}^{\prime} \hat{\beta}\right) \mathbb{1}_{q_{i, t}>c}+v_{i}+\epsilon_{i, t}
$$

Where $q_{i, t}$ denotes the threshold variable (democracy in our context), $c$ the threshold parameters 
and $\mathbb{1}$ is the indicator function defined as follows:

$$
\mathbb{1}_{q_{i, t}>c}= \begin{cases}1 & \text { if } q_{i, t}>c \\ 0 & \text { otherwise }\end{cases}
$$

Our panel threshold model can also be written in a more conventional way as:

$$
G i n i_{i, t}=\left(\gamma_{1} P R P_{i, t}+x_{i, t}^{\prime} \beta_{1}\right) \mathbb{1}_{q_{i, t}>c}+\left(\gamma_{2} P R P_{i, t}+x_{i, t}^{\prime} \beta_{2}\right) \mathbb{1}_{q_{i, t} \leq c}+v_{i}+\epsilon_{i, t}
$$

\subsection{Data and descriptive statistics}

We construct a five-year panel from 1994 to 2014 for 189 of the countries in our property right index sample. ${ }^{14}$ For the dependent variable, Gini, the literature is divided as to whether inequality should take the government's intervention into account. de Haan and Sturm (2017), for example, argue that taxes and transfers distort the analysis of income inequality, while Krieger and Meierrieks (2016) contend that they should be accounted for to better reflect the actual power of the elite. Our estimations will consider both Gini market and Gini net. The former refers to the inequality in market incomes, i.e. the 'amount of money coming into the household, excluding any government cash or near-cash benefits' (Solt, 2016, p.7). ${ }^{15}$ Gini net on the other hand measures the inequality in the disposable income of the families, i.e. the income available after taxes and transfers are accounted for. Following most previous studies (see for example, de Haan and Sturm (2017) and Krieger and Meierrieks (2016)), this study uses the Gini index based on household's income from Solt (2016). It is the most comprehensive database and allows comparison across countries because it standardises income (Delis et al., 2014; de Haan and Sturm, 2017).

Our baseline regressions use the PRP index described above. The results are also compared to three alternative measures of property rights: the Heritage Foundation indicator of property rights (HTF), the Fraser Institute index of the 'strength of the legal system and property rights'

\footnotetext{
${ }^{14}$ Lack of data on inequality forced us to drop two countries from the PRP dataset.

${ }^{15}$ As Solt (2016) points out, this measure of the income distribution is still affected by many other government policies, including e.g. minimum wages.
} 
(FRA), and the Worldwide Governance Indicator's index of the rule of law (WGI). To allow a direct comparison of the results, all indexes were rescaled such that their values lie between 0 and 100 .

Following previous studies (Young and Lawson, 2014, e.g.) we use the Polity IV Project democracy score ( $p_{\_}$democ) as the proxy for democracy. This variable also acts as the transition (or threshold) variable. The Polity IV Project scores a country on the quality of its democratic institutions, putting particular focus on the level of political competition and the constraints on the executive. Scores are on a scale of 0 to 10 , with higher values corresponding to fully institutionalised democracies. ${ }^{16}$ Other covariates include the log of the real GDP per capita (income), secondary school enrolment ratios (human capital), government expenditure as a percentage of GDP (Gov. exp.), the share of agricultural employment (emp. agri.), trade as a percentage of GDP (trade), the share of natural resources in GDP (oil rents) and the KOF index of globalisation. The variables real GDP, the share of agricultural employment, trade and oil rent are obtained from the World Bank World Development Indicators. Secondary school enrolment ratios are taken from the UN and the most recent version of the globalisation index from Dreher (2006). ${ }^{17}$

Following Acemoglu et al. (2013) and Harms and an de Meulen (2013), all the variables on the right hand side are lagged one period to mitigate endogeneity problems. Table 2 lists the summary statistics and sources for all the variables.

\subsection{Results}

Table 3 reports the results of the regressions using the the PRP index derived in this paper. The first two columns report the results for the net income inequality, while the dependent variable in the last two columns was market income inequality.

Before analysing the results, we check the validity of the panel threshold specification. For

\footnotetext{
${ }^{16}$ In addition to being widely used as a proxy for democracy, the Polity IV Project democracy scores offer a wider coverage with fewer missing variables.

${ }^{17}$ As trade is already included in our model, the globalisation index mainly captures financial globalisation.
} 
Table 2: Variables description and summary statistics

\begin{tabular}{|c|c|c|c|c|c|c|c|}
\hline & Description and source & Source & Obs & Mean & St.dev. & Min & Max \\
\hline Gini Market & Market income inequality & SWIID 2016 & 627 & 46.206 & 6.546 & 21.905 & 70.359 \\
\hline HTF & Property rights index & Heritage Foundation & 553 & 48.615 & 23.117 & 7.5 & 95 \\
\hline FRA & Legal property rights & Fraser Institute & 449 & 53.715 & 17.363 & 15.315 & 89.728 \\
\hline WGI & Rule of Law index & Kaufmann et al. (2009) & 744 & 48.723 & 19.745 & 2.08 & 89.4 \\
\hline Human capital & Gross enrolment ration, secondary & WDI & 506 & 74.439 & 31.555 & 5.965 & 159.742 \\
\hline Gov. exp. & Government expenditure (\%GDP) & IMF & 668 & 32.026 & 12.824 & 2.384 & 94.773 \\
\hline Emp. agri. & Share of employment in agriculture & WDI & 558 & 31.082 & 26.411 & 0.356 & 92.416 \\
\hline Trade & Trade (\%GDP) & WDI & 552 & 87.304 & 52.732 & 0.218 & 471.929 \\
\hline Oil rents & Oil rents & WDI & 563 & 3.830 & 10.125 & 0.000 & 62.442 \\
\hline
\end{tabular}

both the Gini net and Gini market, the p-value of the Wald test is 0.000 giving a clear indication that the hull hypothesis of linearity can be rejected. In other words, this implies the adoption of a threshold model is justified.

Turning to our main variable of interest, in the model where the Gini net is the dependent variable, the estimated coefficient of the PRP index is positive and statistically significant for the low democracy countries. Once democracy exceeds the threshold value of 7.39, however, the effect of an increase in the security of property rights becomes negative and significant. The results suggest that in anocracies -a government between a dictatorship and democracy which receive a score democracy score of 5 or lower- and weak democracies, the strengthening of property rights worsens inequality. However, once countries transit to a higher democratic level (around $60 \%$ of the observations), further strengthening of property rights reduces inequality. Along this line, as aforementioned Acemoglu et al. (2013) argue that the government's propensity to redistribute increases with the level of democracy. Therefore, one would expect property rights to reduce inequality as it is the case here.

When using Gini market as the dependent variable, the threshold parameter is higher (8.41) which reduces the fraction of observations corresponding to the high democracy countries to around $50.3 \%$. While the effect of property rights remains positive and statistically significant for the low democracy countries, its effect for the high democracy countries is statistically insignificant. Taken together with the results related to the Gini net, this suggests that property rights reduce inequality via redistribution by the government, providing further support to Acemoglu et al. (2013) and Besley and Persson (2013). 
Table 3: Impact of property rights (PRP) on inequality

\begin{tabular}{|c|c|c|c|c|}
\hline \multirow[b]{2}{*}{ Variables } & \multicolumn{2}{|c|}{ Gini net } & \multicolumn{2}{|c|}{ Gini market } \\
\hline & Low democracy & High democracy & Low democracy & High democracy \\
\hline $\mathbf{P R P}_{t-1}$ & $\begin{array}{c}2.103 * * * \\
(0.519)\end{array}$ & $\begin{array}{c}-0.5356 * * * \\
(0.199)\end{array}$ & $\begin{array}{l}2.511 * * * \\
(0.7961)\end{array}$ & $\begin{array}{l}0.0579 \\
(0.275)\end{array}$ \\
\hline \multicolumn{5}{|l|}{ Control variables } \\
\hline Democracy $_{t-1}$ & $\begin{array}{c}0.311 * * * \\
(0.094)\end{array}$ & $\begin{array}{c}-1.067 * * * \\
(0.319)\end{array}$ & $\begin{array}{c}0.147 * \\
(0.088)\end{array}$ & $\begin{array}{c}-1.229 * * \\
(0.559)\end{array}$ \\
\hline Income $_{t-1}$ & $\begin{array}{c}-1.238 \\
(1.518)\end{array}$ & $\begin{array}{l}0.7415 \\
(1.246)\end{array}$ & $\begin{array}{c}1.243 \\
(1.556)\end{array}$ & $\begin{array}{l}-2.606 \\
(1.991)\end{array}$ \\
\hline Human capital $_{t-1}$ & $\begin{array}{c}0.029 \\
(0.030)\end{array}$ & $\begin{array}{l}-0.045 \\
(0.035)\end{array}$ & $\begin{array}{c}-0.027 \\
(0.024)\end{array}$ & $\begin{array}{c}0.083 * * \\
(0.042)\end{array}$ \\
\hline Gov. exp.t-1 & $\begin{array}{c}0.078 * * * \\
(0.029)\end{array}$ & $\begin{array}{c}-0.229 * * * \\
(0.060)\end{array}$ & $\begin{array}{c}0.0613 * * \\
(0.028)\end{array}$ & $\begin{array}{c}-0.277 * * * \\
(0.085)\end{array}$ \\
\hline Emp. agri $_{\cdot t-1}$ & $\begin{array}{c}-0.238 * * * \\
(0.065)\end{array}$ & $\begin{array}{c}0.314 * * * \\
(0.055)\end{array}$ & $\begin{array}{c}-0.1604 * * \\
(0.062)\end{array}$ & $\begin{array}{c}0.110^{*} \\
(0.065)\end{array}$ \\
\hline Trade $_{t-1}$ & $\begin{array}{c}0.013 \\
(0.013)\end{array}$ & $\begin{array}{c}-0.092 * * * \\
(0.022)\end{array}$ & $\begin{array}{l}0.0216^{*} \\
(0.013)\end{array}$ & $\begin{array}{c}-0.120 * * * \\
(0.035)\end{array}$ \\
\hline Oil rents $t_{t-1}$ & $\begin{array}{c}0.038 \\
(0.058)\end{array}$ & $\begin{array}{c}0.097 \\
(0.266)\end{array}$ & $\begin{array}{l}0.0242 \\
(0.039)\end{array}$ & $\begin{array}{c}0.040 \\
(0.593)\end{array}$ \\
\hline Globalization $_{t-1}$ & $\begin{array}{c}-0.342 * * * \\
(0.075)\end{array}$ & $\begin{array}{c}0.515^{* * * *} \\
(0.098)\end{array}$ & $\begin{array}{c}-0.3144 * * * \\
(0.075)\end{array}$ & $\begin{array}{c}0.622 * * * \\
(0.129)\end{array}$ \\
\hline $\begin{array}{l}\text { Threshold democracy } \\
\text { Obs. above threshold } \\
\text { Wald test [p-value] } \\
\text { Numbers of countries }\end{array}$ & $\begin{array}{r}7 . \\
60 \\
53.16 \\
1\end{array}$ & $\begin{array}{l}39 \\
7 \% \\
0.000] \\
39\end{array}$ & $\begin{array}{r}8 \\
50 \\
30.42 \\
1\end{array}$ & $\begin{array}{l}31 \\
3 \% \\
0.000]\end{array}$ \\
\hline
\end{tabular}

Notes: Heterosckedasticity corrected standard errors in parenthesis, p-values in square brackets; ***, **, * indicate significance at the $1 \%, 5 \%$ and $10 \%$ level; Results obtained using Matlab 16. ${ }^{a}$ Test of the linearity of the model $\left(H_{0}\right.$ : no threshold effect).

Although the focus is on the effect of property rights it may be worth touching on the effect of democracy on inequality. The reported results in all the specifications in Table 3 suggest that democracy increases inequality in low democracy countries, while reducing it in the high democracy countries. This finding is consistent with Simpson (1990), Burkhart (1990) and Justman and Gradstein (1999) who report a non-linear relationship between inequality and democracy. The increasing effect of democracy on inequality in the low democracy countries is also in line with Acemoglu et al. (2013, p.42) who argue that "democratisation in the presence of powerful landed elites may increase inequality."

We now turn attention to the other measures of property rights. Tables 4,5 and 6 portray the results for the Heritage Foundation (HTF), The Fraser Institute (FRA) and the Worldwide Governance Indicators (WGI), respectively. In all three cases, the null hypothesis of no threshold is rejected. Except for the WGI index, using the alternative measures noticeably decreases the 
number of countries in our sample from 189 with the PRP index to 147 with HTF indicator (a $22 \%$ decrease) and 129 with FRA index (a 32\% decrease).

Using the Heritage Foundation's data the results in Table 4 show that property rights exert no discerning statistical effect on inequality when the Gini net is considered. In contrast, the results show that when the Gini market is used as the dependent variable, property rights increases inequality in the low democracy countries and decreases it in the high democracy countries. These results clearly imply property rights only affect inequality at the market level and that the redistribution by the government reveres these effects. The results are in clear contrast to the finding in this paper where property rights reduce inequality only via redistribution.

The results in Table 5 show that irrespective of whether the Gini net or the Gini market is considered, the effect of the Fraser Institute's index on inequality is statistically significant. In lower democracies, property rights increase inequality and in the higher democracies they reduce it. In contrast to the PRP index, the results using the Fraser Institute's index seem to indicate that the government's redistribution worsens the effect of property rights on inequality. Indeed, government redistribution tends to magnify the increasing effect of property rights (FRA) on inequality in low democracies; whilst in high democracies it decreases the extent to which inequality is reduced. Overall, the effect of property rights also tends to be smaller when using the FRA index, particularly in the case of the low democracy countries, where the difference is such that the $95 \%$ confidence intervals of the indicators does not overlap (Figure 4).

Finally, Table 6 show that when the WGI index is used, property rights exert no statistically significant effect on inequality, whether before or after distribution. All the estimated coefficients are small and not statistically significant. 
Table 4: Impact of the Heritage Foundation's indicator on inequality

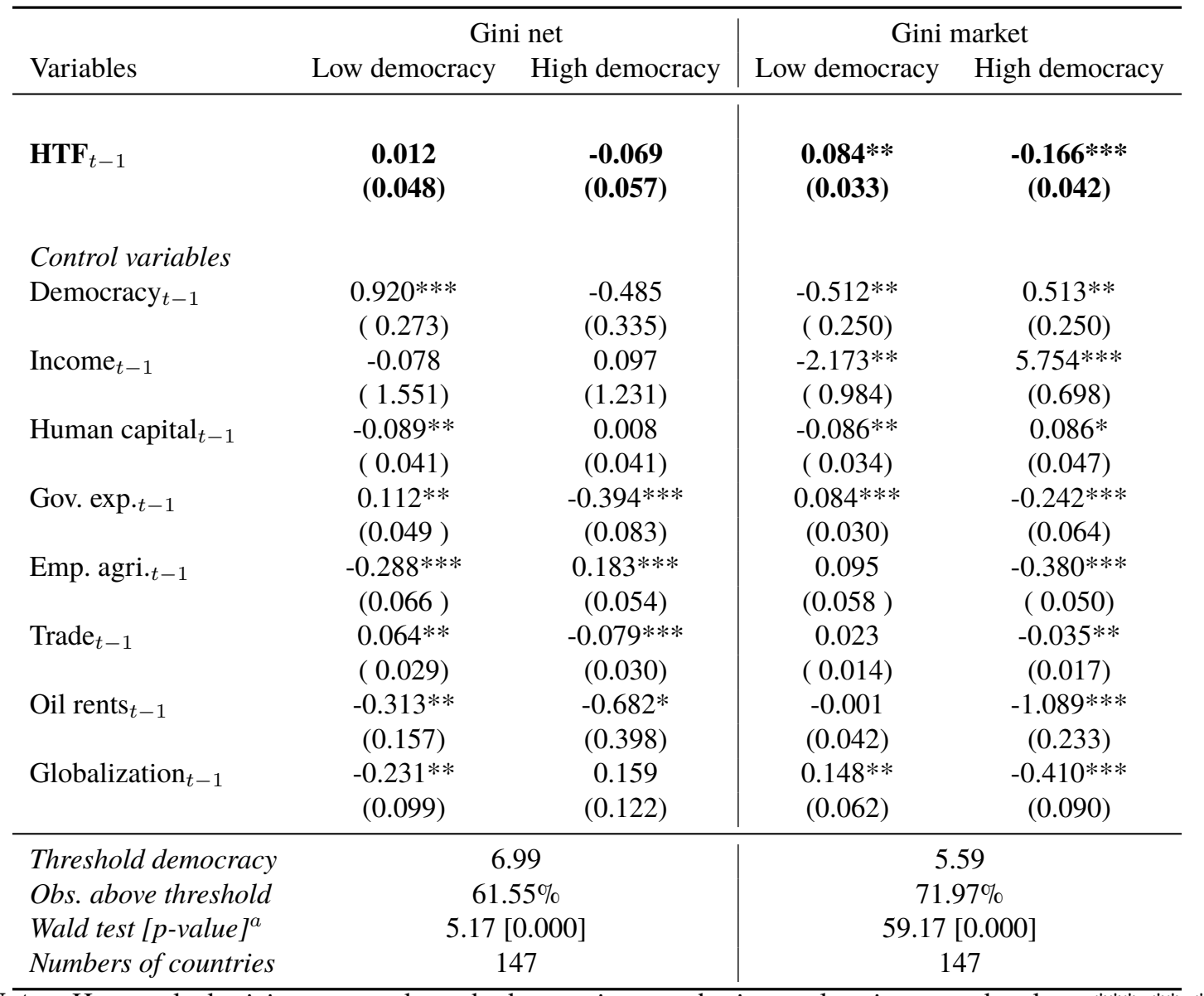

Notes: Heterosckedasticity corrected standard errors in parenthesis, p-values in square brackets; ***, **, * indicate significance at the $1 \%, 5 \%$ and $10 \%$ level; Results obtained using Matlab 16. ${ }^{a}$ Test of the linearity of the model $\left(H_{0}\right.$ : no threshold effect). 
Table 5: Impact of the Fraser Institute's index on inequality

\begin{tabular}{|c|c|c|c|c|}
\hline \multirow[b]{2}{*}{ Variables } & \multicolumn{2}{|c|}{ Gini net } & \multicolumn{2}{|c|}{ Gini market } \\
\hline & Low democracy & High democracy & Low democracy & High democracy \\
\hline $\mathbf{F R} \mathbf{A}_{t-1}$ & $\begin{array}{c}0.223 * * * \\
(0.053)\end{array}$ & $\begin{array}{c}-0.443 * * * \\
(0.088)\end{array}$ & $\begin{array}{c}0.196 * * * \\
(0.056)\end{array}$ & $\begin{array}{c}-0.609 * * * \\
(0.150)\end{array}$ \\
\hline \multicolumn{5}{|l|}{ Control variables } \\
\hline Democracy $_{t-1}$ & $\begin{array}{l}0.308 * * \\
(0.134)\end{array}$ & $\begin{array}{c}0.962 \\
(0.875)\end{array}$ & $\begin{array}{c}0.319 * * * \\
(0.117)\end{array}$ & $\begin{array}{c}2.278 \\
(1.878)\end{array}$ \\
\hline Income $_{t-1}$ & $\begin{array}{c}0.643 \\
(1.442)\end{array}$ & $\begin{array}{c}-0.702 \\
(1.367)\end{array}$ & $\begin{array}{c}2.089 \\
(1.443)\end{array}$ & $\begin{array}{c}-0.792 \\
(2.397)\end{array}$ \\
\hline Human capital $_{t-1}$ & $\begin{array}{c}-0.184 * * * \\
(0.037)\end{array}$ & $\begin{array}{c}0.222 * * * \\
(0.042)\end{array}$ & $\begin{array}{c}-0.115^{* * *} \\
(0.031)\end{array}$ & $\begin{array}{c}0.214 * * * \\
(0.060)\end{array}$ \\
\hline Gov. exp. $\cdot t-1$ & $\begin{array}{l}-0.081 \\
(0.065)\end{array}$ & $\begin{array}{l}-0.151^{*} \\
(0.086)\end{array}$ & $\begin{array}{l}-0.022 \\
(0.063)\end{array}$ & $\begin{array}{l}-0.219^{*} \\
(0.129)\end{array}$ \\
\hline Emp. agri. $t-1$ & $\begin{array}{c}-0.185 * * * \\
(0.045)\end{array}$ & $\begin{array}{c}0.335 * * * \\
(0.079)\end{array}$ & $\begin{array}{c}-0.122 * * \\
(0.051)\end{array}$ & $\begin{array}{l}0.316^{* *} \\
(0.136)\end{array}$ \\
\hline Trade $_{t-1}$ & $\begin{array}{l}0.054 * * \\
(0.023)\end{array}$ & $\begin{array}{l}-0.041^{*} \\
(0.025)\end{array}$ & $\begin{array}{c}0.091 * * * \\
(0.025)\end{array}$ & $\begin{array}{c}-0.128 * * * \\
(0.037)\end{array}$ \\
\hline Oil rents $t_{t-1}$ & $\begin{array}{c}-0.239 * * \\
(0.113)\end{array}$ & $\begin{array}{c}-0.491 \\
(0.536)\end{array}$ & $\begin{array}{c}-0.248^{* *} \\
(0.103)\end{array}$ & $\begin{array}{c}0.117 \\
(0.909)\end{array}$ \\
\hline Globalization $_{t-1}$ & $\begin{array}{l}-0.089 \\
(0.083)\end{array}$ & $\begin{array}{c}0.043 \\
(0.118)\end{array}$ & $\begin{array}{c}-0.190 * * * \\
(0.072)\end{array}$ & $\begin{array}{c}0.241 \\
(0.170)\end{array}$ \\
\hline Threshold democracy & & 61 & & \\
\hline Obs. above threshold & & $0 \%$ & 31. & $8 \%$ \\
\hline Wald test [p-value $]^{a}$ & 44.96 & {$[0.000]$} & 38.37 & $0.000]$ \\
\hline Numbers of countries & & 29 & & \\
\hline
\end{tabular}

Notes: Heterosckedasticity corrected standard errors in parenthesis, p-values in square brackets; ***, **, * indicate significance at the $1 \%, 5 \%$ and $10 \%$ level; Results obtained using Matlab 16. ${ }^{a}$ Test of the linearity of the model $\left(H_{0}\right.$ : no threshold effect). 
Table 6: Impact of the WGI's index on inequality

\begin{tabular}{|c|c|c|c|c|}
\hline \multirow[b]{2}{*}{ Variables } & \multicolumn{2}{|c|}{ Gini net } & \multicolumn{2}{|c|}{ Gini market } \\
\hline & Low democracy & High democracy & Low democracy & High democracy \\
\hline $\mathbf{W G} \mathbf{I}_{t-1}$ & $\begin{array}{c}0.064 \\
(0.056)\end{array}$ & $\begin{array}{l}-\mathbf{0 . 0 3 7} \\
(\mathbf{0 . 0 6 1 )}\end{array}$ & $\begin{array}{c}\mathbf{0 . 0 3 7} \\
(\mathbf{0 . 0 6 7})\end{array}$ & $\begin{array}{c}0.014 \\
(0.071)\end{array}$ \\
\hline \multicolumn{5}{|l|}{ Control variables } \\
\hline Democracy $_{t-1}$ & $\begin{array}{l}0.324 * * \\
(0.133)\end{array}$ & $\begin{array}{c}-1.464 * * * \\
(0.442)\end{array}$ & $\begin{array}{c}0.355^{* * *} * \\
(0.145)\end{array}$ & $\begin{array}{c}-2.145^{* * *} \\
(0.500)\end{array}$ \\
\hline Income $_{t-1}$ & $\begin{array}{c}2.685^{*} \\
(1.530)\end{array}$ & $\begin{array}{c}-1.452 * * \\
(0.691)\end{array}$ & $\begin{array}{c}1.863 \\
(1.766)\end{array}$ & $\begin{array}{l}-1.107 \\
(0.778)\end{array}$ \\
\hline Human capital $_{t-1}$ & $\begin{array}{c}-0.017 \\
(0.033)\end{array}$ & $\begin{array}{l}-0.018 \\
(0.034)\end{array}$ & $\begin{array}{c}-0.015 \\
(0.039)\end{array}$ & $\begin{array}{c}0.001 \\
(0.039)\end{array}$ \\
\hline Gov. exp. $\cdot t-1$ & $\begin{array}{l}0.066^{*} \\
(0.037)\end{array}$ & $\begin{array}{c}-0.261 * * * \\
(0.086)\end{array}$ & $\begin{array}{l}0.070^{*} \\
(0.042)\end{array}$ & $\begin{array}{c}-0.257 * * * \\
(0.094)\end{array}$ \\
\hline Emp. agri $_{t-1}$ & $\begin{array}{c}-0.213 * * * \\
(0.074)\end{array}$ & $\begin{array}{c}0.219 * * * \\
(0.051)\end{array}$ & $\begin{array}{c}-0.315 * * * \\
(0.083)\end{array}$ & $\begin{array}{l}0.134 * * \\
(0.058)\end{array}$ \\
\hline Trade $_{t-1}$ & $\begin{array}{c}0.025 \\
(0.021)\end{array}$ & $\begin{array}{c}-0.080 * * * \\
(0.029)\end{array}$ & $\begin{array}{c}0.028 \\
(0.023)\end{array}$ & $\begin{array}{c}-0.075^{* *} \\
(0.032)\end{array}$ \\
\hline Oil rents $t_{t-1}$ & $\begin{array}{l}-0.006 \\
(0.055)\end{array}$ & $\begin{array}{l}0.0 .010 \\
(0.398)\end{array}$ & $\begin{array}{c}0.009 \\
(0.051)\end{array}$ & $\begin{array}{l}-0.212 \\
(0.311\end{array}$ \\
\hline Globalization $_{t-1}$ & $\begin{array}{c}-0.387 * * * \\
(0.101)\end{array}$ & $\begin{array}{c}0.489 * * * \\
(0.118)\end{array}$ & $\begin{array}{c}-0.406^{* * *} \\
(0.117)\end{array}$ & $\begin{array}{c}0.524 * * * \\
(0.135)\end{array}$ \\
\hline $\begin{array}{l}\text { Threshold democracy } \\
\text { Obs. above threshold } \\
\text { Wald test stat. [p-value] } \\
\text { Numbers of countries }\end{array}$ & $\begin{array}{r}7 \\
60 . \\
44.35 \\
1\end{array}$ & $\begin{array}{l}37 \\
8 \% \\
0.000] \\
6\end{array}$ & $\begin{array}{r}7 \\
60 . \\
45.39 \\
1\end{array}$ & $\begin{array}{l}37 \\
8 \% \\
0.000] \\
36\end{array}$ \\
\hline
\end{tabular}

Notes: Heterosckedasticity corrected standard errors in parenthesis, p-values in square brackets; $* * *, * *, *$ indicate significance at the 1\%,5\% and 10\% level; Results obtained using Matlab 16. ${ }^{a}$ Test of the linearity of the model $\left(H_{0}\right.$ : no threshold effect). 


\subsection{Discussion}

To get a clear sense of the difference between our proposed PRP and alternative measures we first start by directly comparing not just their sign and significance but also the size of their coefficient estimates. To that end, Figure 4 juxtaposes the coefficients estimates and $95 \%$ confidence intervals. As detailed in section 4.3, the indicators of property rights used in these regressions have been rescaled such that their theoretical boundaries are 0 , no protection and 100 , complete protection. This reveals the following patterns. In the case of WGI, property rights have no effect on inequality. The Heritage Foundation's index does find a significant effect, but it is very small and disappears completely once government redistribution is accounted for. The findings using the FRA index are much more closely aligned with those using the new PRP index. A key difference is that the Fraser Institute's index suggests that government redistribution increases inequality. The PRP index on the other hand indicates that the reduction in inequality through stronger property rights is only achieved via the government's redistribution. Moreover, for low democracy countries, the effect of property rights is a lot stronger when using the PRP index and the difference is big enough that the confidence intervals no longer overlap.

While the theoretical bounds of the indicators is the same, their sample distribution can still be markedly different. The second way in which we compare these indicators is by standardising them according to their sample distribution. The results are summarised in Table 7, showing e.g. that an increase in property rights of one standard deviation in low democracy countries increases the net-income Gini coefficient by almost one standard deviation $(0.95)$ when using the PRP index. The size of this effect is 1.5 times larger than the estimates using the Fraser Institute's index, 32 times those of the Heritage Foundation and 6 times that of the Worldwide Governance Indicators. Compared to figure 4, the differences between the size of the coefficients has shrunk considerably as the sample standard deviation of the PRP index is significantly smaller than that of the other indicators (cf. Table 9). We would argue that this is an essential attribute of the PRP index caused by our definition of property rights and the way in which the indicators are combined. 

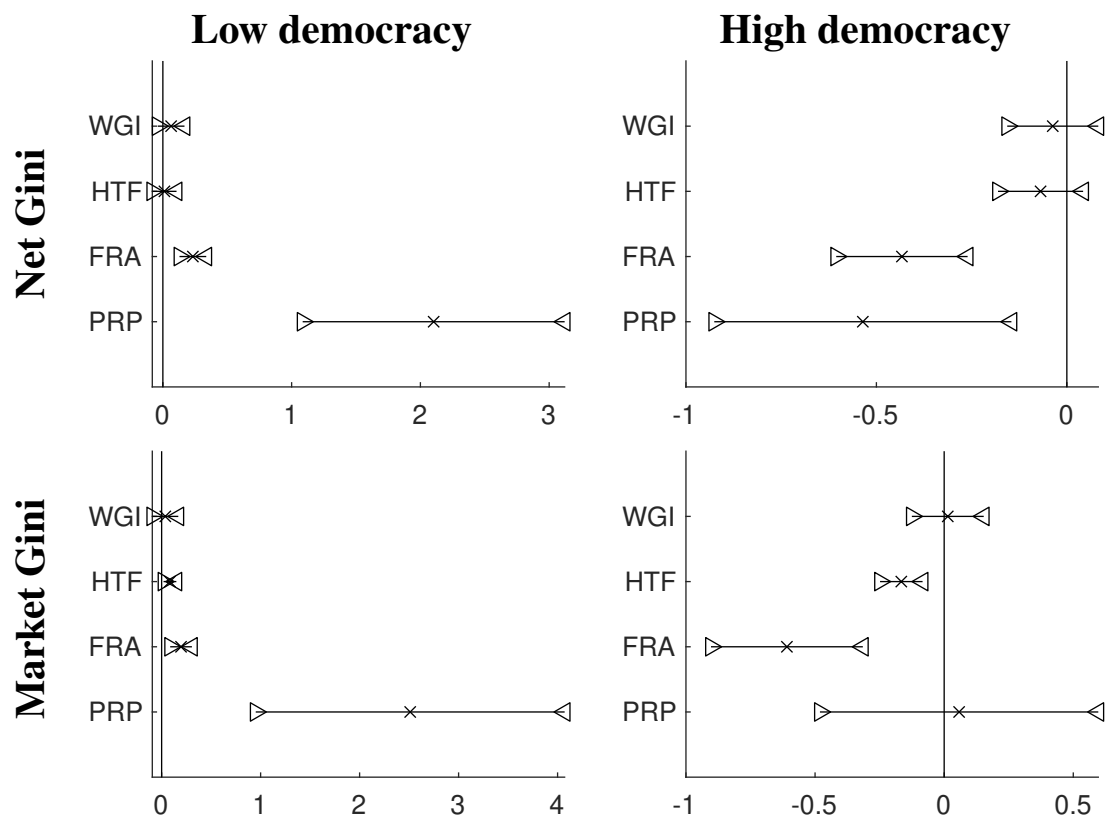

Figure 4: Comparison of the coefficients on property rights

Point estimate $(\times)$ and $95 \%$ confidence interval $(\triangleright \triangleleft)$ of the coefficient of property rights when using the PRP

(Table 3), FRA (Table 5), HTF (Table 4) and WGI indexes (Table 6).

Table 7: Standardised coefficients using sample distributions

\begin{tabular}{ccccc}
\hline & \multicolumn{2}{c}{ Gini net } & \multicolumn{2}{c}{ Gini market } \\
\hline PRP & 0.95 & -0.24 & 1.39 & 0.03 \\
FRA & 0.64 & -1.27 & 0.69 & -2.15 \\
HTF & 0.03 & -0.15 & 0.22 & -0.44 \\
WGI & 0.16 & -0.09 & 0.11 & 0.04
\end{tabular}

This table shows the change in the Gini index expressed as a multiple of its standard deviation, following an increase in property rights of one standard deviation. It is based on the results using the PRP (Table 3), FRA

(Table 5), HTF (Table 4) and WGI indexes (Table 6).

There are other major differences between the PRP index and the alternative indexes that can explain the differences in our findings. Firstly, the PRP index is based on a more strict definition of property rights that purges other elements such as those measuring 'the success of a society in developing an environment in which fair and predictable rules form the basis for economic and social interactions' (Teorell et al., 2019, p.657). Within that restriction, the PRP index includes all available indicators of property rights from a variety of sources including commercial risk agencies, surveys and think tanks. Secondly, the way in which this information is combined, using a state-space model, makes optimal use of the strong time-dependence in the protection of property rights. This allows for a bettering filtering of the actual movements in property rights protection from random measurement error in the data. 
Another major difference is that the proposed PRP index also offers a wider coverage (with no missing observations) compared to alternative measures. In fact, relative to FRA and HTF, the PRP index constitutes a significant increase in the coverage of the dataset (respectively a $15 \%$ and $45 \%$ increase)

Finally, the finding that the reducing effect of property rights (PRP) on inequality is achieved only via redistribution is intuitively plausible. To be sure, some studies (see Walder, 1992; Besley and Persson, 2013) show that the distributive role of government is crucial for reduction in inequality when discussing property rights. Also, from a practical viewpoint, and in the context of higher democracies, markets are not generally set up in a way that strengthening property rights will automatically redistribute resources from those whose rights are strongly protected to the less-protected hands. Government redistribution is perhaps the most effective way to achieve this (Palda, 1999). In summary, democratic governments not only strengthen property rights but concurrently, negate any resulting non-inclusive outcomes, such as rising income inequality, by increasing the size of government (via taxation) and redistributing. Along these lines, Acemoglu et al. (2013) note that the effect of property rights interacts with democracy, as the latter influences the government's propensity to redistribute.

\section{Conclusion}

Empirical testing of the impact of property rights on various outcomes, most particularly inequality, remains an area of interest for many researchers in social sciences. However, as many empirical studies have acknowledged, existing measures of property rights suffer from various issues, ranging from a lack of accuracy and gaps in coverage to measuring the more-broadly defined rule-of-law. In this paper, we tried to close this gap by providing a new measure of property rights that circumvents most of the aforementioned issues. Indeed, our new property rights index combines 18 indicators from various sources that strictly capture the security of property rights. As these indicators not only have their strengths and weaknesses but also capture various aspects of property rights, we argue that combining them into a single indicator would help in obtaining a more reliable measure of property rights.

To construct the index, we use the state-space model that takes the temporal dependence 
of property rights into account. Moreover, the technique is robust to missing variables and is arguably better suited for the use in panel data analyses. Our index of property rights covers 191 countries from 1994-2014. Undeniably, it significantly improves on data availability relative to existing widely used index such as the Heritage Foundation (15\% increase) and the Fraser Institute Index (45\% increase).

We used the new proposed data to assess the interlink between property rights, democracy, and inequality and compare the results with the existing measures of property rights. Our empirical analysis is based on a threshold panel technique with fixed effects where our democracy is the transition (threshold) variable. The results based on the new index show that securing property rights reduces inequality in higher democracies only via the governments' redistribution. In contrast, alternative indicators appear to indicate that the redistributive role of the government either does not affect the way property rights influence income inequality or even increases income inequality.

We hope that our dataset will provide a platform for social scientists to explore the link between property rights and various outcomes.

\section{References}

D. Acemoglu, S. Naidu, P. Restrepo, and J. A. Robinson. Democracy, redistribution and inequality. Technical report, National Bureau of Economic Research, 2013.

A. Amendola, J. Easaw, and A. Savoia. Inequality in developing economies: the role of institutional development. Public Choice, 155(1-2):43-60, 2013.

D. L. Bennett and B. Nokolaev. On th ambiguous economic freedom-inequality relationship. Empirical Economics, 53:717-754, 2017.

T. J. Besley and T. Persson. Taxation and development. Technical report, CEPR discussion paper, 2013.

R. D. Burkhart. Comparative democracy and income distribution: Shape and direction of the causal arrow. Journal of Politics, 59:148-164, 1990. 
F. Carmignani. The distributive effects of institutional quality when government stability is endogenous. European Journal of Political Economy, pages 409-421, 2009.

A. Chong and M. Gradstein. Inequality and institutions. The Review of Economics and Statistics, 89(3):454-465, 2007.

J. de Haan and J.-E. Sturm. Income inequality, capitalism, and ethno-linguistic fractionalization. American Economic Review: Papers \& Proceedings, 105:593-597, 2015.

J. de Haan and J.-E. Sturm. Finance and income inequality: A review and new evidence. European Journal of Political Economy, 50:171-195, 2017.

M. D. Delis, I. Hasan, and P. Kasakis. Bank regulations and income inequality: empirical evidence. Review of Finance, 18:1811-1846, 2014.

R. Desbordes and G. Koop. Should we care about the uncertainty around measures of politicaleconomic development? Journal of Comparative Economics, 2015.

A. Dreher. Does globalization affect growth? evidence from a new index of globalization. Applied Economics, 38(10):1091-1110, 2006.

J. Fouquau, C. Hurlin, and I. Rabaud. The feldstein-horioka puzzle: a panel smooth transition regression approach. Economic Modelling, 52:284-299, 2008.

J. C. Ginarte and W. G. Park. Determinants of patent rights: A cross-national study. Research policy, 26(3):283-301, 1997.

A. A. Goldsmith. Democracy, property rights and economic growth. The Journal of Development Studies, 32(2):157-174, 1995.

J. Gwartney, R. Lawson, J. Hall, and R. Murphy. Economic freedom of the world. Technical report, Cato Institute, 2019.

P. Harms and P. an de Meulen. Demographic structure and the security of property rights: The role of development and democracy. European Journal of Political Economy, 59:73-89, 2013. 
M. Justman and M. Gradstein. The democratization of political elites and the decline in inequality in modern economic growth. In S. Breizes, Elise and P. Temin, editors, Elites, Minorities and Economic Growth. Elsevier, 1999.

D. Kaufmann, A. Kraay, and M. Mastruzzi. Governance matters viii: aggregate and individual governance indicators, 1996-2008. World bank policy research working paper, 4978, 2009.

C.-J. Kim, C. R. Nelson, et al. State-space models with regime switching: classical and Gibbssampling approaches with applications, volume 2. MIT press Cambridge, MA, 1999.

G. Koop. Bayesian Econometrics. John Wiley \& Sons Ltd, Chichester, 2003.

T. Krieger and D. Meierrieks. Political capitalism: The interaction between income inequality, economic freedom and democracy. European Journal of Political Economy, 45:115-132, 2016.

C.-S. Lee. Income inequality, democracy, and public sector size. American Sociological Review, 70(1):158-181, 2005.

M. Levi. Of Rule and Revenue. California University Press, 1988.

H. Li, L. Squire, and H.-f. Zou. Explaining international and intertemporal variations in income inequality. The Economic Journal, 108(446):26-43, 1998.

K. E. Maskus and M. Penubarti. How trade-related are intellectual property rights? Journal of International Economics, 39(3):227-248, 1995.

B. E. Moon. The political economy of basic human needs. Cornell University Press, 1991.

E. N. Muller. Democracy, economic development, and income inequality. American Sociological Review, pages 50-68, 1988.

F. Palda. Property rights vs. redistribution: Which path to national wealth? Public Choice, 101: 129âĂŞ145, 1999.

T. Piketty. Capital in the Twenty First Century. Boston, Harvard University Press, 2013. 
R. Reuveny and Q. Li. Economic openness, democracy, and income inequality an empirical analysis. Comparative Political Studies, 36(5):575-601, 2003.

D. Rodrik. Where did all the growth go? external shocks, social conflict, and growth collapses. Journal of economic growth, 4(4):385-412, 1999.

P. H. Schneider. International trade, economic growth and intellectual property rights: A panel data study of developed and developing countries. Journal of Development Economics, 78 (2):529-547, 2005.

I. Sened. The Political Institution of Private Property. Cambridge University Press, 1997.

M. Simpson. Political rights and income inequality: A cross-national test. American Sociological Review, 55:682-693, 1990.

L. Sirowy and A. Inkeles. The effects of democracy on economic growth and inequality: A review. Studies in Comparative International Development, 25(1):126-157, 1990.

F. Solt. The standardized world income inequality database. Social Science Quarterly, 2016.

S. Standaert. Divining the level of corruption: a bayesian state-space approach. Journal of Comparative Economics, 43(3):782-803, 2015.

J. Teorell, M. Samanni, S. Holmberg, and B. Rothstein. The qog standard dataset. Technical report, University of Gothenburg: The Quality of Government Institute, 2013.

J. Teorell, S. Dahlberg, S. Holmberg, B. Rothstein, N. A. Pachon, and R. Svensson. The quality of government standard dataset codebook. Technical report, University of Gothenburg: The Quality of Government Institute, 2019.

T. van de Klundert. On the determinants of institutional design. European Journal of Political Economy, 26:167-175, 2010.

A. G. Walder. Property rights and stratification in socialist redistributive economies. American Sociological Review, 57:524-539, 1992. 
A. T. Young and R. A. Lawson. Capitalism and labor shares: A cross-country panel study. European Journal of Political Economy, 33:20-36, 2014. 


\section{Appendix A Data sources and description}

Table 8: Sources and definitions of indicators of the security of property rights

\begin{tabular}{|c|c|}
\hline \multicolumn{2}{|c|}{ Economist Intelligence Unit - Market Indicators and Forecasts } \\
\hline EIU1 & Intellectual Property Rights Protection \\
\hline EIU2 & Property Rights protection \\
\hline \multicolumn{2}{|c|}{ World Economic Forum - Global Competitiveness Report } \\
\hline GCS1 & Intellectual Property Rights Protection \\
\hline GCS2 & Property Rights \\
\hline \multicolumn{2}{|c|}{ Heritage Foundation - Index of Economic Freedom } \\
\hline HTF & Protection of Property Rights \\
\hline \multicolumn{2}{|c|}{ IHS - Global Insight } \\
\hline IHS & Risk of Expropriation \\
\hline \multicolumn{2}{|c|}{ CEPII Institutional profiles database } \\
\hline IPD1 & Effectiveness of legal measures to defend property rights between private agents \\
\hline IPD2 & Does the government exert arbitrary pressure on private property? \\
\hline IPD3 & Compensation in the event of [..] expropriation of land property? \\
\hline IPD4 & Compensation in the event of [..] expropriation of property for production? \\
\hline IPD5 & Intellectual property protection in terms of manufacturing secrets, patents, etc. \\
\hline IPD6 & Intellectual property protection in terms of counterfeiting \\
\hline IPD7 & Does the State recognise formally the diversity of land tenure system? \\
\hline
\end{tabular}

\begin{tabular}{|c|c|}
\hline \multicolumn{2}{|c|}{ Institute for Management Development - World Cor } \\
\hline WCY1 & Intellectual property rights are adequately e \\
\hline WCY2 & Personal security and private property ri \\
\hline Countr & Policy and Institutional As \\
\hline & Property rights and rule-based governance \\
\hline $\operatorname{ADB}^{(a)}$ & African Development Bank \\
\hline $\operatorname{ASD}^{(a)}$ & Asian Development Bank \\
\hline $\operatorname{WBD}^{(a)}$ & World Bank \\
\hline
\end{tabular}

Fraser Institute - Protection of Property rights

FRA $^{(b)} \quad$ Property Rights and Rule-based Governance

Ginarte and Park (1997)
$\mathrm{GP}^{(b)} \quad$ Index of patent rights

Kaufmann et al. (2009) - Worldwide Governance Indicators

$\mathrm{WGI}^{(b)} \quad$ Rule of law

(a) Not included in the strict index of property rights (cf. section 3.1 and Appendix B.3)

(b) Not included in the PRP index (cf. section 3.1).

\section{Appendix B Estimating the security of property rights}

\section{B.1 Gibbs sampling algorithm}

In order to estimate the security of property rights, we construct a state-space model by combining equations 1-10 from section 3.2. To write this model in a more concise form, we first order 
Table 9: Summary statistics of the indicators of property rights

\begin{tabular}{|c|c|c|c|c|c|c|c|c|c|}
\hline & Obs & Years & Cntries & Mean & St.dev. & $\begin{array}{c}\text { Theoretical } \\
\text { range }\end{array}$ & $\begin{array}{c}\text { Sample } \\
\text { range }\end{array}$ & $\begin{array}{c}\text { Truncated } \\
(\%)^{(a)}\end{array}$ & $\begin{array}{c}\text { Unique } \\
\text { values }(b)\end{array}$ \\
\hline EIU1 & 1257 & $1995-2015$ & 60 & 3.236 & 1.271 & {$[1,5]$} & {$[1,5]$} & 31 & 16 \\
\hline EIU2 & 1257 & $1995-2015$ & 60 & 3.927 & 1.122 & {$[1,5]$} & {$[1,5]$} & 45 & 18 \\
\hline GCS1 & 1369 & $2006-2015$ & 151 & 3.8 & 1.142 & {$[1,7]$} & {$[1.58,6.48]$} & 0 & 1363 \\
\hline GCS2 & 1369 & $2006-2015$ & 151 & 4.425 & 1.061 & {$[1,7]$} & {$[1.52,6.67]$} & 0 & 1363 \\
\hline HTF & 3161 & $1994-2013$ & 180 & 4.779 & 2.4 & {$[0,10]$} & {$[0,9.5]$} & 0.03 & 20 \\
\hline IHS & 189 & 2015 & 189 & 8.104 & 1.153 & {$[0,10]$} & {$[0.1,6.9]$} & 0 & 43 \\
\hline IPD1 & 396 & $2001-2012$ & 141 & 2.586 & 0.981 & {$[1,4]$} & {$[1,4]$} & 36 & 4 \\
\hline IPD2 & 380 & $2001-2012$ & 143 & 2.613 & 0.994 & {$[1,4]$} & {$[1,4]$} & 37 & 4 \\
\hline IPD3 & 390 & $2001-2012$ & 143 & 2.713 & 0.975 & {$[1,4]$} & {$[1,4]$} & 37 & 4 \\
\hline IPD4 & 366 & $2001-2012$ & 143 & 2.779 & 0.991 & {$[1,4]$} & {$[1,4]$} & 40 & 4 \\
\hline IPD5 & 392 & $2001-2012$ & 141 & 2.298 & 1.068 & {$[1,4]$} & {$[1,4]$} & 46 & 4 \\
\hline IPD6 & 383 & $2001-2012$ & 139 & 2.083 & 1.072 & {$[1,4]$} & {$[1,4]$} & 53 & 4 \\
\hline IPD7 & 228 & $2009-2012$ & 139 & 2.984 & 0.998 & {$[1,4]$} & {$[1,4]$} & 47 & 7 \\
\hline WCY1 & 1114 & $1995-2015$ & 61 & 6.113 & 1.711 & {$[0,10]$} & {$[0.11,9.72]$} & 0 & 674 \\
\hline WCY2 & 1114 & $1995-2015$ & 61 & 6.257 & 2.195 & {$[0,10]$} & {$[1.17,9.15]$} & 0 & 631 \\
\hline ADB & 433 & $2004-2014$ & 40 & 3.07 & 0.745 & {$[1,6]$} & {$[1,5]$} & 2 & 28 \\
\hline ASD & 250 & $2006-2014$ & 31 & 3.392 & 0.686 & {$[1,6]$} & {$[1.5,5]$} & 0 & 8 \\
\hline WBD & 761 & $2005-2014$ & 81 & 2.9 & 0.639 & {$[1,6]$} & {$[1,4]$} & 0.5 & 7 \\
\hline
\end{tabular}

(a) Percentage of the data that is equal to either the theoretical minimum or maximum.

(b) Total number of unique values occurring in the dataset.

the variables according to their type: continuous $\left(a_{1}, \ldots, A\right)$, truncated $\left(b_{1}, \ldots, B\right)$ or ordered $\left(c_{1}, \ldots, C\right)$. We can then construct the vectors $\mathbf{Y}_{i, t}$ and $\tilde{\mathbf{Y}}_{i, t}$ by stacking the (latent) indicator variables:

$$
\begin{aligned}
& \mathbf{Y}_{i, t}=\left[y_{i, t}^{a_{1}}, \ldots, y_{i, t}^{A}, y_{i, t}^{b_{1}}, \ldots, y_{i, t}^{B}, y_{i, t}^{c_{1}}, \ldots, y_{i, t}^{C}\right]^{\prime} \\
& \tilde{\mathbf{Y}}_{i, t}=\left[y_{i, t}^{a_{1}}, \ldots, y_{i, t}^{A}, \tilde{y}_{i, t}^{b_{1}}, \ldots, \tilde{y}_{i, t}^{B}, \tilde{y}_{i, t}^{c_{1}}, \ldots, \tilde{y}_{i, t}^{C}\right]^{\prime}
\end{aligned}
$$

This allows us to rewrite the state and measurement equations into the following Gaussian statespace model:

$$
\begin{aligned}
\tilde{\mathbf{Y}}_{i, t} & =\mathbf{C}+\mathbf{Z} P R P_{i, t}+\mathbf{e}_{i, t} \\
P R P_{i, t} & =\phi_{i} P R P_{i, t-1}+\mu_{i, t} \\
\mathbf{e}_{i, t} & \sim N\left(0, \Sigma_{\epsilon}\right) \\
\mu_{i, t} & \sim N(0,1)
\end{aligned}
$$




$$
\begin{aligned}
& \forall b \in\left\{b_{1}, \ldots, B\right\}: y_{i, t}^{b}= \begin{cases}l^{b} & \text { if } \quad \tilde{y}_{i, t}^{b} \leq l^{b} \\
\tilde{y}_{i, t}^{b} & \text { if } l^{b}<\tilde{y}_{i, t}^{b}<u^{b} \\
u^{b} \text { otherwise }\end{cases} \\
& \forall c \in\left\{c_{1}, \ldots, C\right\}: y_{i, t}^{c}=j \text { if } \gamma_{j-1}^{c}<\tilde{y}_{i, t}^{c}<\gamma_{j}^{c}
\end{aligned}
$$

where $\mathbf{C}=\left[c^{a_{1}}, \ldots, c^{C}\right]^{\prime}, \mathbf{Z}=\left[z^{a_{1}}, \ldots, z^{C}\right]^{\prime}, \mathbf{e}_{i, t}=\left[\epsilon_{i, t}^{a_{1}}, \ldots, \epsilon_{i, t}^{C}\right]^{\prime}$ and $\Sigma_{\epsilon}$ is a diagonal matrix where the diagonal is formed by $\left[\sigma_{\epsilon}^{a_{1}}, \ldots, \sigma_{\epsilon}^{C}\right]$.

In order to estimate this model, we do not only have to determine the most likely values of the PRP index, but also those of the latent variables, $\left(\tilde{y}^{b_{1}}, \ldots, \tilde{y}^{C}\right)$ as well as those of the parameters of the model $\left(\mathbf{c}, \mathbf{z}, \Sigma_{\epsilon}\right.$ and $\left.\gamma_{1}^{c_{1}}, \ldots, \gamma_{J}^{C}\right)$. To simplify this problem, we use a Bayesian Gibbs sampling approach, which allows us to split up the estimation problem using conditional distributions that are much easier to determine and draw from.

In our example, the estimation problem can be split up into four main blocks. ${ }^{18}$ First, conditional on $P R P$ and $\tilde{\mathbf{Y}}$, the parameters of Equations 15 and 16 can be determined using linear regressions. Second, conditional on $\tilde{y}^{c}$ the values of $\gamma$ can be drawn from a uniform distribution (Koop, 2003, p. 220). Third, conditional on PRP, C, $\mathbf{Z}$ and $\sigma_{\epsilon}$, the values of the latent indicator variables can be drawn from a truncated normal distribution ( , p. 212 and 220). Finally, given the latent indicator variables and the parameter values, the security of property rights can be estimated and drawn from using a Kalman filter and smoother as detailed in Kim et al. (1999, chapter 8).

A Gibbs sampler is a Monte Carlo Markov Chain algorithm that iteratively draws from these conditional probabilities while conditioning on the drawn values of the other parameters. For most well-behaved distributions, it can be shown that these draws will eventually converge to the unconditional, to-be-estimated distribution. See e.g. Koop (2003) for an introduction to Bayesian Econometrics and Gibbs sampling. As Gibbs sampling is a technique from Bayesian econometrics, we have to specify our prior assumptions on the parameters. Given that we did not have any ex-ante information, we simply imposed uninformative priors.

\footnotetext{
${ }^{18}$ For notational convenience, we will omit the subscript to indicate the entire vector: e.g. $\mathbf{Y}=$ $\left[Y_{1,1}^{\prime}, \ldots, Y_{1, T}^{\prime}, \ldots, Y_{n, T}^{\prime}\right]^{\prime}$, where $n$ and $T$ are the total number of countries and years.
} 
Starting from a simple average of the indicators, the Gibbs sampling algorithm iteratively draws from the following conditional probabilities:

1. Draw $\mathbf{C}, \mathbf{Z}, \Sigma_{\epsilon}$ and $\phi_{i}$ conditional on $P R P$ and $\tilde{\mathbf{Y}}$.

For each $\tilde{y}$ in $\tilde{\mathbf{Y}}$, we estimated the parameters of the measurement equation, $c, z$ and $\sigma$, using a pooled linear regression: ${ }^{19}$

- $[c ; z] \sim N\left(\left(X^{\prime} X\right)^{t-1} X^{\prime} \tilde{y} ; \sigma_{\epsilon}\right)$, where $X=[\mathbf{1}, P R P]$

- $\sigma \sim i$ Wish $\left(e^{\prime} e ; n * T\right)$ where $e=\tilde{y}-c-z P R P$. However, for the ordered variables, $\sigma$ was normalised to 1 in order to identify the model.

The time persistence parameter $\phi_{i}$ is estimated for each country separately. Since $\phi_{i}$ is restricted to lie in the interval $[-1,1]$, it has to be drawn from a truncated normal distribution. If $P R P_{i}$ is the vector of the property rights index for country $i$ for all time-periods and $P R P_{i,-1}$, the conditional distribution of $\phi_{i}$ is:

- $\phi_{i} \sim N\left(p \bar{h} i_{i} ; 1\right) \mathbb{1}_{\left|\phi_{i}\right| \leq 1}$, where $p \bar{h} i_{i}=\left(P R P_{i,-1}^{\prime} P R P_{i,-1}\right)^{t-1} P R P_{i,-1}^{\prime} P R P_{i}$ and for identification's sake $\sigma_{\mu}$ is normalised to 1 (cf. supra).

2. Draw $\gamma$ conditional on $\tilde{\mathbf{Y}}$ and $\tilde{\mathbf{Y}}$.

The values of $\gamma$ can be drawn separately for each $y \in\left\{y^{c_{1}}, \ldots, y^{C}\right\}$. As was explained in section 3.2, the first two and the last value of $\gamma$ is always the same: $\gamma_{0}=-\infty, \gamma_{1}=0$ and $\gamma_{J}=\infty$. The remaining $\gamma_{j}$ of each variable $y$ are drawn from a uniform distribution (Koop, 2003, p. 212):

$$
\begin{aligned}
\gamma_{j} & \sim U\left(\underline{\gamma}_{j}, \bar{\gamma}_{j}\right) \quad \forall j \in\{2, \ldots, J-1\} \\
\underline{\gamma}_{j} & =\max \left\{\max \left\{\tilde{y}_{i, t} \mid y_{i, t}=j\right\} ; \gamma_{j-1},\right\} \\
\bar{\gamma}_{j} & =\min \left\{\min \left\{\tilde{y}_{i, t} \mid y_{i, t}=j+1\right\} ; \gamma_{j+1},\right\}
\end{aligned}
$$

${ }^{19}$ While the model resembles a Seemingly Unrelated Regression, the overabundance of missing values ensures that we cannot estimate the parameters for all indicators simultaneously. However, as the dependent variable is the same for all indicators, running the estimation for each indicator separately is functionally identical. 
3. Draw $\tilde{\mathbf{Y}}$ conditional on $\mathbf{C}, \mathbf{Z}, \Sigma_{\epsilon}, \gamma$ and $P R P$.

- For each $y \in\left\{y^{b_{1}}, \ldots, y^{B}\right\}$, the values of its latent variable, $\tilde{y}$ are the same as $y$ whenever $y$ lies in between the lower (l) and upper (u) bounds. For the remaining observations, the values of the latent variable are drawn from a truncated normal distribution, conditional on the parameters of its measurement equation, $c, z$ and $\sigma$ (Koop, 2003, p. 212):

$$
\begin{array}{ll}
\tilde{y}_{i, t} \sim N\left(c+z P R P_{i, t} ; \sigma\right) \mathbb{1}_{\tilde{y}_{i, t} \leq l} \quad \text { if } y_{i, t}=l \\
\tilde{y}_{i, t} \sim N\left(c+z P R P_{i, t} ; \sigma\right) \mathbb{1}_{\tilde{y}_{i, t} \geq u} & \text { if } y_{i, t}=u
\end{array}
$$

- For each $y \in\left\{y^{c_{1}}, \ldots, y^{C}\right\}$, the values of its latent variable are drawn from a truncated normal distribution, conditional on the parameters of its measurement equation $(c, z$ and $\sigma$ ) and its values of $\gamma$ (Koop, 2003, p. 220):

$$
\tilde{y}_{i, t} \sim N\left(c+z P R P_{i, t} ; \sigma\right) \mathbb{1}_{\gamma_{j-1}<\tilde{y}_{i, t} \leq \gamma_{j}} \quad \text { if } y_{i, t}=j
$$

4. Draw $P R P$ using a simulation smoother conditional on $\tilde{\mathbf{Y}}, \mathbf{C}, \mathbf{Z}, \Sigma_{\epsilon}$ and $\sigma_{\mu}$.

Given the parameters of the state and measurement equation and the values of the (latent) indicator variables, we can use a Kalman filter and simulation smoother to draw new values of the PRP index for each country separately. For a detailed explanation of the Kalman filter and smoother, see Kim et al. (1999, chapter 8).

The Kalman filter computes the expected value and variance of state variable that takes into account all information up to that point. Starting from an initial random guess $\left(a_{0} \sim\right.$ $N(0, \infty))$, it iterates forward over all observations $t=1, \ldots, T$ in the model in the following way:

$$
\begin{aligned}
a_{i, t \mid t} & =E\left(P R P_{i, t} \mid \tilde{y}_{i, 1}, \ldots, \tilde{y}_{i, t}\right) \\
& =\phi_{i} a_{t-1 \mid t-1}+\kappa\left(y_{t}-\mathbf{C}-\mathbf{Z} \phi_{i} a_{t-1 \mid t-1}\right) \\
p_{i, t \mid t} & =\operatorname{var}\left(P R P_{i, t} \mid \tilde{y}_{i, 1}, \ldots, \tilde{y}_{i, t}\right)
\end{aligned}
$$




$$
=p_{t \mid t-1}+\kappa \mathbf{Z} p_{t-1 \mid t-1}
$$

with $\kappa=p_{i, t \mid t-1} \mathbf{Z}^{\prime}\left(\mathbf{Z} p_{i, t \mid t-1} \mathbf{Z}^{\prime}+\Sigma_{\epsilon}\right)^{t-1}$; and $p_{i, t \mid t-1}=\phi_{i} p_{i, t-1 \mid t-1} \phi_{i}^{\prime}+\sigma_{\mu}$.

Having run through the entire dataset, the final iteration of the Kalman filter returns the distribution of the index in the last observation that takes into account all information in the dataset: $a_{i, T \mid T}$ and $p_{i, T \mid T} \cdot{ }^{20}$ By subsequently iterating backward in the simulation smoother, we can ensure that the previous observations also take all information into account. The simulation smoother also draws a value of the state-variable in each iteration, to ensure that consistency of the draws. Starting with a new draw of $P R P_{i, T} \sim$ $N\left(a_{i, T \mid T}, p_{i, T \mid T}\right)$, the simulation smoother iterates backwards from $t=T-1$ to 1 .

$$
\begin{aligned}
a_{i, t \mid T} & =E\left(P R P_{i, t} \mid \tilde{y}_{i, 1}, \ldots \tilde{y}_{i, T}\right) \\
& =a_{t \mid t}+\Omega\left(\hat{a}_{t+1 \mid n}-\phi_{i} a_{t \mid t}\right) \\
p_{i, t \mid T} & =\operatorname{var}\left(P R P_{i, t} \mid \tilde{y}_{i, 1}, \ldots \tilde{y}_{i, T}\right) \\
& =p_{t \mid t}+\Omega\left(p_{t+1 \mid n}-\phi_{i} p_{t \mid t} \phi_{i}^{\prime}-Q\right) \Omega^{\prime}
\end{aligned}
$$

with $\Omega=p_{t \mid t} \phi_{i}^{\prime} p_{t+1 \mid t}^{t-1}$; and $\hat{a}_{t+1 \mid n}$ a random draw from $N\left(a_{t+1 \mid n} ; p_{t+1 \mid n}\right)$.

We estimated the model by running this algorithm for 50,000 iterations of which the first 40,000 were discarded as burn-in. Convergence was checked using CUMSUM and ACF graphs.

\section{B.2 Normalising the index}

The PRP index is a scale variable, meaning that the absolute value of the index does not really have a clear interpretation, but changes over time and differences between countries do. The precise values that are returned by the Gibbs sampling algorithm are determined by the identifying assumption that the standard deviation of the error term in the state-equation is one. However,

\footnotetext{
${ }^{20} \mathrm{As}$ we are assuming that $P R P$ follows a normal distribution, the entire distribution is defined using the first two moments.
} 
these can be rescaled as desired, as long as the relative differences of the scores remain unaffected.

To increase the interpretability of the index, we rescale it such that the theoretical minimum score is 0 and the theoretical maximum score is 100: i.e., a country that has the lowest possible score in all years should have a score of zero, and vice versa. To that end, we generate data for two fictional countries, one with all highest scores in all years and one with all the lowest scores, and compute what their index scores would have been in each iteration of the algorithm. This gives us the theoretical minimum and maximum scores, allowing us to rescale the index such that a country with the minimum (maximum) score gets 0 (100).

\section{B.3 Robustness of the index}

\section{B.3.1 Indicator selection}

In order to test the robustness of our specification, we estimated a number of different specifications to see how they affect our results. The different models were compared by looking at the correlation between the baseline index and the new index. To see how they affect the reliability of the index values, we also computed the correlation between the standard deviations of both indexes. The first two robustness tests are centered on the selection of the singular indicators.

The first test checked whether there is one indicator that distorts the results or had a disproportionate impact on the resulting index. To that end, we recomputed the index 18 times, each time leaving out a different indicator. For most variables, the change in the selection has little to no effect on the resulting index. The correlation between the expected values of the baseline index and the leave-one-out indexes is in excess of 0.98 and more often than not higher than 0.99. Similarly, the effect on the precision of the index tends to be small: the correlation between the standard errors is more than 0.94 for most variables. There are only two variables whose exclusion has a larger effect on the resulting index: the world bank's CPIA (WBD) and index of the Heritage Foundation (HTF). Leaving out WBD has a slightly larger impact on both the expected values and standard deviations, lowering their correlation to 0.98 and 0.89 , respectively. Leaving our HTF has a much bigger impact: it reduces the number of observations in the dataset with $31 \%$ and drops 10 countries from the dataset. The size of the estimated standard 
deviations increases and the correlation with the standard deviation in the baseline model drops to 0.79 . That being said, the correlation between the baseline PRP index and the index without HTF is still 0.99 .

The second check concerns the inclusion of the Country Policy and Institutional Assessment indicators (ADB, ASD, and WBD) that besides measuring the security of property rights also measure the strength of the rule of law. The so-called strict PRP index is limited to those indicators that only measure property rights. While the effect on the resulting index is larger than was the case for the leave-one-out indexes, the results are still very similar. The correlation between the baseline index and the strict index is 0.98 , and the correlation between the standard deviations is 0.87 .

\section{B.3.2 Modelling choices}

The remaining robustness checks concern the specific modelling choices of the state-space model. First, we check how the results are affected when the indicators are grouped per source, similar to Kaufmann et al. (2009) who take the average of all available indicators in each year. The main reason why those authors do this is to reduce the number of missing values. However, in this dataset, it only reduces the fraction of missing values from $80 \%$ to $67 \%$. Another reason for grouping the indicators is that it implicitly accounts for cross-correlation in the error terms of variables coming from the same source. On the other hand, it also introduces new errors as changes in the grouped index can be caused by an increase or decrease in the availability of indicators from that source. Moreover, grouping the indicators hides the underlying variability of the data from that sources.

A direct result of grouping the property rights indicators is that there are no more ordered variables and only one truncated variable. Secondly, because there are now 7 indicators left, we have to impose the same reliability on all indicators. Otherwise, the algorithm simply picks the most abundant indicator (HTF) as the true signal. To impose the same reliability, we first normalise all indicators (mean zero and standard deviation one) and impose that their measurement error has same variance $\left(\sigma_{\epsilon}^{y}=\sigma_{\epsilon} \forall y\right.$ ). The grouped index turns out to be very similar to our baseline results: the correlation between the index and the standard deviation is 0.98 and 0.88 , 
respectively.

The second robustness check looks at our treatment of the ordered variables. Specifically, we look at the effect of only treating variables with 4 unique values of less as ordered probit (IPD1-IPD6), treating those with 7 and 8 unique values as continuous (i.e., IPD7, ASD, and WBD). However, both indexes are practically identical (correlations in excess of 0.99).

Thirdly, we look into the assumption on the time-persistence in the security of property rights. As Figure 5 shows, the level of persistence is always positive in many cases approaches unity. Moreover, in those cases where the mean value of this parameter is less than 0.8 , the standard deviation of the parameter estimate increases, meaning that a unit root is not necessarily ruled out. Therefore we test how the results are affected when we impose that the PRP index has a unit root $\left(\phi_{i}=1\right)$. While this has little effect on the expected value of the index (correlation $>0.99)$, it has significant consequences for the estimated reliability of the results. Assuming a unit root significantly raises the estimated standard deviation of the index with $20 \%$ and lowers the correlation between the standard deviations to 0.67 .

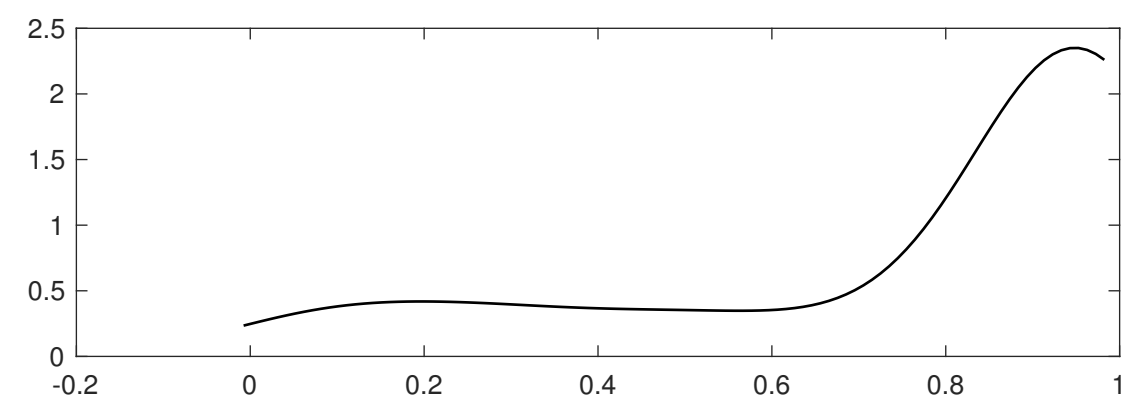

Figure 5: Distribution of $\phi_{i}$ for all $i$.

Kernel density function estimate of the distribution of the expected value of the $\phi_{i}$ parameter.

Finally, we have also computed the PRP index without using a Kalman smoother. The Kalman smoother uses future information on the security of property rights to correct our current estimates. This could conceivably create endogeneity problems when using the index in subsequent analyses. To that end, we recomputed the PRP index without Kalman smoother (but using the same parameter values, $C, Z, \sigma_{\epsilon}$ and $\gamma$ ). The resulting index did not differ from our baseline results (correlation $>0.996$ ). The only effect was an increase in the uncertainty of the index: the average size of the estimated standard deviations increased with $15 \%$. 